\title{
La producción agrícola fronteriza 1977-1981: un análisis estructural
}

\author{
Arturo Ranfla González \\ Instituto de Investigaciones Sociales \\ Universidad Autónoma de Baja California
}

\section{Resumen}

Este trabajo constituye un intento por estudiar la estructura de la producción agrícola regional y un ensayo por medir la sensibilidad de los estados fronterizos con respecto al mercado externo e interno utilizando modelos del análisis regional, tratando de ir más allá de la pura descripción, buscando inferir a través de un estudio descriptivo, una explicación más general sobre los mecanismos intervinientes. De acuerdo a los resultados de este análisis en el Estado de Baja California, se sugiere un alto grado de integración con respecto al exterior, lo cual se manifiesta en menor proporción en la agricultura de riego de las entidades de Tamaulipas y Nuevo León, lo que nos lleva a sugerir la importancia que tiene analizar en una secuencia similar los distritos de riego fronterizos.

Palabras clave: mercado interno, mercado externo, integración nacional, diversificación de productos, agricultura fronteriza.

\begin{abstract}
This work means an attempt to study the structure of regional agriculture production and it is also an essay to measure how sensible the states from the Mexican border are to external and internal market. Simple regional models of analysis will be used to achieve these objectives, but looking for bigger results than just the mere description. Then get a conclusion and a general explanation on the intervening mechanisms. According to the outcome obtained from this analysis performed in the state of Baja California. We suggest a high degree of integration in relation to the exterior one, which shows that irrigation agriculture is used in a lower proportion in the states of Tamaulipas and Nuevo León. Finally, the suggestion is that it is critical to analyze the diverse irrigation districts from the border by following a similar sequence.
\end{abstract}

Keywords: internal market, foreign market, national integration, diversification of products, border agriculture. 


\section{LA PRODUCCION AGRICOLA FRONTERIZA 1977 - 1981; \\ UN ANALISIS ESTRUCTURAL. \\ Por \\ Arturo Ranfla Gonzále, * \\ Investigador del Instituto de Invetigaciones Sociales UABC}

\section{INTRODUCCION}

Es un lugar común hablar de la integración técnica y económica de la agricultura fronteriza con respecto al mercado estadounidensc y últimamentc al mercado in ternacional. Sin embargo, es poco frecuente encontrar estudios estructurales de la producción y longitudinales en virtud de lo errático del comportamiento de la actividad, para su verificación. Frente a este vacío, nuestro trabajo constituye un intento por cstu diar la estructura de la producción agrícola regional y un ensayo por medir la sensibilidad de los estados tronterizos con respecto al mercado externo c interno utilizando modelos muy sencillos del análisis regional.

\section{CARACTERISTICAS DEL PROBLEMA Y METODO DE ANALISIS}

\section{La agricultura fronteriza.}

La complejidad de las relaciones entre México y Estados Unidos, incluye la transformación de la agricultura mexicana y la integración de la producción agrícola a través de la frontera que separa los dos países. Esto, que no constituye un fenómeno aislado, sino la expresión particular de la internacionalización del capital. Destaca la inserción temprana de la región fronteriza del norte de México a este proceso, tanto en la expresión mercantil, que inclina a señalar la integración del universo de consumidores de bienes estadounidenses, ${ }^{1}$ tanto a la internacionalización de la producción agrícola fronteriza, que constituye el objeto de nuestro análisis.

La apertura hacia el exterior que constituye la característica de la agricultura fronteriza, es un factor que conviene destacar, y señalar su temprana inserción al proceso de internacionalización del capital. Proceso de carácter dialéctico de articulación-desarticulación de la acumulación que se desarrolla en ambos países de una manera general. Define de una manera específica, el papel que juegan la agricultura y la alimentación en las relaciones entre paíscs sentrales y periféricos. ${ }^{2}$

Históricamente, el proceso de articulación de la región es largo y tiene sus orígenes en las primeras inversiones norteamericanas en el extranjero que

Investigador del Instituto de Investigaciones Sociales UABC

1 Tamayo J y Fernández J.L.,Zonas fronterizas (México-Estados Unidos), CiDE, México, 1983, pp. 63-119.

${ }^{2}$ De Janvry A., The agrarian question and reformism in Latin American, The Johns Hopkins University Press, Baltimore, 1981, pp.181 
se realizan en las últimas décadas del siglo XIX. ${ }^{3}$ El movimiento de capitales norteamericanos en la región, no deja de realizarse desde este momento, sin embargo, las cambiantes condiciones y sus modalidades nos permiten distinguir dos etapas:

La primera etapa, que tiene un carácter territorial, convierte a la región fronteriza en un apéndice de la frontera norteamericana. Tiene lugar en un momento en que la introducción del ferrocarril permitía la exacción de volúmenes importantes de materias primas del in terior del país, mientras por otra parte, capitales norteamericanos fluían y se apropiaban de extensos territorios en el norte de México al amparo de la política porfiriana de colonización. Esta última, que perseguía de forma deliberada la integración nacional y colonización de la frontera norte, que terminó por llevar la expansión de la frontera norteamericana hasta los fértiles valles de la costa del Pacífico. ${ }^{4}$

La segunda etapa, más que una in tegración territorial, tiene un carácter organizacional. Reflejando principalmente, el efecto de la capitalización de grandes unidades de irrigación por parte del gobierno mexicano y empresarios agrícolas; el abandono de una política agraria populista principalmente en los estados fronterizos, 5 y el proceso de internacionalización del capital productivo en la agricultura, siendo evidente que esta serie de factores no están desvinculados, dieron lugar a la intensificación capitalista de las unidades de producción y la inserción regional en la división internacional del trabajo agrícola.

Dos fuentes están al origen de la intensificación capitalista de la agricultura fronteriza. La primera, representada por las fuertes inversiones públicas

\footnotetext{
${ }_{3}^{3}$ "Después de 1880 - escribió Kirkland - las comunicaciones ferroviarias con Mexico hicieron caer definitivamente a csà nación dentro de la órbita norteamericana. Las inversiones de los Estados Unidos trazaban el campo del dominio político. Hacia 1897 - un año antes del Tratado de Paris - eran como sigue: Canadá, 189 700; Cuba, 49 000 000; América Central y del Sur, 50000000 ; Europa, 151000000 ; Asia, principalmente China, 23000000 y México, la mayor inversión 202000000 dólares... En 1897, se daban los primeros pasos del imperialismo". Entre 1897 y 1908, la inversión norteamericana en México se incrementó en $\mathbf{4 7 2 0 0 0} 000$ de dólares. Lo que significó un aumento de $236.0 \%$, y constituyó para ese último año el $26.6 \%$ del total invertido por los Estados Unidos en el mundo. García Cantú G., Las invaciones norteamericanas en México, Editorial ERA, Mexico 19, pp. 223-233. Según otras estimaciones de carácter interregional e intersectorial de las inversiones norteamericanas en el pais, se estima que el $66.7 \%$ de las inversiones norteamericanas no ferrocarrileras en el pais se localizan en los estados fronterizos. Distribuyéndose este total de inversiones no ferrocarrileras un $62.0 \%$ en la mineria; $18.3 \%$ en la agricultura; $6.5 \%$ en manufacturas; $4.5 \%$ en banca; $4.5 \%$ en refinerias de fundicion y $3.9 \%$ en servicios. Fernández R. La frontera México-Estados Unidos, un estudio socioeconómico, Ed. Terranova, México, 1980, pp. 106-107.
}

4 Sanderson S.E., Trade aspects of the internationalization of mexican agriculture: consequences for Mexico's food crisis, Center for U.S. Mexican Studies, Monograph Series 10, UCSD, 1983, pp. 35.

5 "Los estados de la frontera norte, a excepción de Baja Calífornia, son las entidades en las que la pro. piedad privada tiene la supremacía, no sólo por los valores relativos que este tipo de propiedad presenta, sino por el hecho de que esas cinco entidades, Sonora, Chihuahua, Coahuila, Nuevo León y Tamaulipas, absorben más de la mitad de toda la superficie privada del país: 39.3 millones de hectá. reas". Coll-Hurtado A., ¿Es México un pats agricola? Un análisis geográfico. Siglo XXI Eds., México, 1982 , pp. 52 . 
en infraestructura de irrigación por parte de los gobiernos posrevolucionarios, condición de existencia para que la región se vinculara al capital desplazándose de los Estados Unidos. La segunda, constituida por la rápida implementación a nivel de las unidades de producción al proceso de modernización. Este último proceso favorecido, tanto por la banca privada como pública, como parte de un esfuerzo para aumentar las exportaciones apoyando incluso con financiamiento a las empresas extranjeras que invertían en nuestro país. ${ }^{6}$

Ambos grupos de factores contribuyeron a que en cerca de cuarenta años más tarde, los grandes territorios desérticos de los seis estados fronteri$z o s$, el $45 \%$ fuera de riego. Proporción que casi duplicaba la que se había dado a nivel nacional para 1981 , que fue del $24.7 \%$. La fuerte proporción de superficies de riego en la mayoría de los estados fronterizos, que como en el caso de Sonora alcanzó el $97.0 \%$ y Baja California 94.0\%, favoreció la concentración de superficies de labor y la económica de las explotaciones. Un ejemplo de esto lo tenemos en 1970 , año para el que el $44.6 \%$ del valor de la producción nacional se había generado en superficies mayores de cinco hectáreas a nivel nacional. La proporción fue en Baja California del $52.9 \%$; Sonora, $73.2 \%$; Chihuahua, $67.2 \%$; Coahuila, $40.4 \%$; Nuevo León, $78.9 \%$ y Tamaulipas, $60.8 \%$. De la misma manera, mientras la proporción de capital constante por unidad de producción había sido de $53.1 \%$ para cada uno de los estados fronterizos, fue de 74.0\% para Baja California, 70.0\% en Sonora, $58.9 \%$ en Chihuahua, $54.0 \%$ en Coahuila, $51.2 \%$ en Nuevo León y $63.0 \%$ en Tamaulipas. ${ }^{7}$

Consecuencia de las fuertes inversiones en infraestructura de riego en los últimos cuarenta años y la rápida capitalizacion de las unidades de producción, se convierten en las condiciones de existencia que vinculan a la agricultura regional con la agricultura norteamericana a través del capital. Este, por su misma necesidad de expansión, concurrencia y valorización requiere de transformaciones tecnológicas, de expansión de mercados y de integrar tasas diferentes en la explotación de la fuerza de trabajo. ${ }^{8}$

La lógica de valorización del capital como pieza clave del proceso de articulación del sector regional a la nueva división internacional del trabajo agrícola, la inserta en un sistema organizado en términos de una especialización en la producción de alimentos y materias primas, como un medio de restructuración del proceso de acumulación a nivel mundial. Esta articulación conduce a transformaciones estructurales que no se limitan únicamente al

- Cardera M.E., Patrón monetario y acumulación en México, nacionalización y control de cambios, Sipo XXI Eds, Mćxico, 1984, pp.59.

T Censo Agrtcola, Ganadero y Ejidal, SiC, México, 1975.

5 Palloix Ch., L'Economie mondiale capitaliste el lex firmes multinationales. Masfero, París, 1975, T 2 77. 71: Mandel E., El capítalismo tardto, Ed. ERA 1979, pp. 84-96. 
sector agrícola y que reflejan los cambios internos, experimentados e implantados en el país copartícipe, en este caso, los Estados Unidos. ${ }^{9}$

En estas condiciones, los cambios reponden a las modificaciones estructurales de las condiciones internas de valorización del capital en ambos paises, catalizados por la presencia de la línea fronteriza. Esto nos sugiere que d núcleo central de la articulación histórica del sector agropecuario entre los dos países lo constituya la tendencia declinante de las tasas de beneficic de las actividades primarias en los Estados Unidos, como resultado de los incrementos experimentados por los insumos y la renta del suelo. Mientras, el déficit estructural de la balanza le pagos en México ha promovido un fomento secular del sector público con respecto a los puntos de exportación, promoción materializada a través de las inversiones en infraestructura de riego que ha socializado el costo de la renta del suelo para el usuario directo del mismo, así como su apoyo directo e indirecto para la capitalización y operación de producción a través de los sistemas público y privado de crédito.

Es en este marco, que se inscribe la región dentro de un proceso internacional de especialización en la producción de alimentos, manejado como un sector estratégico tanto en los países centrales como periféricos, dando lugar asía un conflicto entre la protección a su producción agrícola y su internacionalización en los países centrales y a la necesidad de expansión de una agricultura de exportación, la promoción de agribussiness y las inversiones multinacionales en los países periféricos. ${ }^{10}$

\section{Método de análisis.}

La articulación de la producción agrícola y pecuaria entre Estados Unidos y México se desarrolla por medio de una serie de interacciones que no se limitan a la circulación de bienes sino también al proceso de producción. Esta forma de articulación da lugar a que este sector de la actividad económica fronteriza dé muestras de una marcada especialización, resultado de sus fuertes interacciones con un importante sector de la economía norteamericana e internacional, haciendo que esta especialización no se desligue del desarrollo comercial, el agribussiness, la contratación y el financiamiento externo.

Esta serie de características tiende a repercutir en la configuración de una estructura "básica" de la producción agrícola fronteriza. De una manera general, la estructura básica del sector agrícola tiene rasgos que la diferencian de las configuraciones de carácter industrial y urbano en el plano técnico y

\footnotetext{
10 Sanderson S.E, op. cit., p.44.

9 “However it was Nixon's 1971 New Económic Policy, with his emphasis on agricultural export expansion, which succeeded in bringing agriculture out of the 1968 slump'. De Janvry A., op. cit., p.178.
} 
temporal. En efecto, en la producción agrícola la reconversión de cultivos se puede suceder de un año a otro e inclusive de un ciclo a otro, dando lugar a modificaciones sustanciales de las interrelaciones intrasectoriales e intersectoriales, que generan transformaciones en las configuraciones originales. Estas características propias del sector podrían interpretarse como un obstáculo para análisis longitudinales. Sin embargo, por las fuertes inversiones comprometidas en la región, el carácter comercial de la producción y la orientación hacia el exterior de una parte sustancial de la misma, nos llevan a proponer un análisis estructural del sector agrícola fronterizo siguiendo las características de la producción y de su orientación. Es así que con base en un catálogo de 149 productos, elaborado a partir de los productos registrados en los anuarios de la producción agrícola nacional, ${ }^{11}$ procedimos a definir sucesivamente una estructura por función de cada uno de los productos, conformada en ocho grupos: granos, otras alimenticias, forrajeras, oleaginosas, textiles, industriales, cítricos, otros frutales y varios. Se definieron también estructuras parciales definidas con respecto a la orientación de mercado de los mismos, con base en los criterios de exportación directa, 12 indirecta 13 y de una dieta básica ideal14 para consumo interno, con el objetivo general de analizar la estructura productiva regional y subregional (definida por cada estado fronterizo), así como ponderar el peso relativo que tienen los productos según su orientación hacia el consumo externo o interno, entre las estructuras nacional y regional (interregional) y regional-estatal (intrarregional). 15

El procedimiento, en virtud de la diversificación de los productos y su distribución geográfica, favorece la definición de una estructura según una estandarización de productos y localización. Esto quiere decir que la estructura se define como una combinación de productos con relación a un espacio dado y para un período dado; éste último, en virtud de la disponibilidad estadística, es de un año. Este criterio nos permite definir conjuntos y subconjuntos de carácter espacial, que van a diferenciarse por su composición interna con respecto a los otros. Las estructuras de producción nacional, regional y estatal (subregionales) son hipotéticamente iguales (comparables) y en la práctica diferentes. En consecuencia, nuestro objetivo es identificar el grado y la naturaleza de la diferencia.

Este objetivo, siendo muy ambicioso, está condicionado a la existencia de información muy desagregada - de la cual disponemos para un período de

\footnotetext{
11 SARH, SAO, DGEA, Producción Agrícola Nacional, Anuarios estadisticos, 1977, 78, 79, 80, 81.

12 Incluye sandia, pepino, berenjena, brócoli, uva, garbanzo, algodón, ajonjolí, cebollín, espárrago, calab acita, lechuga, tomate, chile, col de Bruselas, ajo, fresa, cebolla, ocra.

13 En esta clasificación ubicamos a los forrajes.

14 Incluye una dieta básica ideal constituida por maíz, trigo, arroz, frijol, papa, tomate rojo, chile seco, chile verde, cebolla, lechuga, zanahoria, plátano, limón, manzana, cártamo, girasol, soya. Necesidades esenciales en México, Alimentación, Coplamar, Siglo XXI Eds., México, 1982.

15 Para fines del análisis, las tres escalas son el pais, la región como suma de los estados y las subregiones constituidas por cada uno de los estados.
} 
cinco años-así como al uso de técnicas sencillas que permitan el manejo de un volumen importante de información, en términos de comparación de productos y de distribución geográfica, siendo esto último posible utilizando técnicas propias al análisis regional. Esto nos llevó a partir de las unidades homogéneas de análisis (producción nacional, regional y estatal) densificadas e términos de las superficies cosechadas ${ }^{16}$ y valor de la producción, para integrarse a dos procedimientos de estandarización posibles: ${ }^{17}$

a) De estructura

$$
\frac{\mathrm{Na}}{\mathrm{N}}, \frac{\mathrm{Ni}}{\mathrm{N}}, \frac{\mathrm{Nai}}{\mathrm{Na}} \frac{\mathrm{Nai}}{\mathrm{Ni}}
$$

b) De crecimiento

$$
\frac{\mathrm{dNa}}{\mathrm{Na}}-\frac{\mathrm{dN}}{\mathrm{N}}, \frac{\mathrm{dNi}}{\mathrm{Ni}}-\frac{\mathrm{dN}}{\mathrm{N}},\left(\frac{\mathrm{dNai}}{\mathrm{Nai}}-\frac{\mathrm{dNi}}{\mathrm{Ni}}\right),\left(\frac{\mathrm{dNai}}{\mathrm{Nai}}-\frac{\mathrm{dN}}{\mathrm{N}}\right)
$$

Ambos grupos permiten derivar valores anuales (discretos) y del período 1977-81 (continuo). Los cuales se realizan a través de los cocientes de localización y de cambio participativo, que se finalizan de la manera siguiente:

$$
\text { b) } \frac{\mathrm{dNa}}{\mathrm{Na}} \cdot \frac{\mathrm{dN}}{\mathrm{N}}=\left[\frac{\mathrm{dNa}}{\mathrm{Na}}-{ }_{\mathrm{i}}^{\mathrm{n}} \sum_{\mathrm{i}}^{\mathrm{Na}}\left(\frac{\mathrm{dNi}}{\mathrm{Ni}}\right) \cdot \frac{\mathrm{Nai}}{\mathrm{Na}}\right]+\left[\left(\frac{\mathrm{dNi}}{\mathrm{Ni}}\right) \frac{\mathrm{Nai}}{\mathrm{Na}}-\frac{\mathrm{dN}}{\mathrm{N}}\right]
$$

Cada uno de ellos mide la relación proporcional entre la participación regional y la participación nacional con respecto a la superficie o valor cosechado de un bien $i(i=1, \ldots, 149)$. Se obtienen en el primer caso, valores que destacan la magnitud del carácter superavitario (exportador) o deficitario (importador) de las relaciones con respecto a la unidad ${ }^{18}$ homogénea mayor.

\footnotetext{
16 Se utilizó el concepto de superficie cosechada, evacuándose automáticamente el riesgo en la pro. ducción. Esta determinación obedeció a la necesidad de evitar variaciones importantes derivadas de fenómenos naturales.

17 Bishop K.C. and Simpson C.E., "Components of change analysis: problems of alternative approaches to industrial structure", Regional Studies, Vol, 6, pp. 59-68 (1972), pp.62. Los literales utilizados tienen el siguiente significado:

$\mathrm{N}=$ Superficie cosechada o valor (V) a nivel nacional.

$\mathrm{Na}=$ Superficie cosechada o valot (V) en la región a

$\mathrm{Ni}=$ Superficie cosechada o valor (V) del producto $i$ a nivel nacional.

Nai= Superficie cosechada o valor (V) del producto i en la región a.

18 Florance P.S. et. al "Measures of industrial distribution", in Industrial location and national ressources, U.S. Natural Ressources Board, Washington, D.C., 1943.
} 
Para el segundo caso, las diferencias del cambio entre las variaciones de la superficie y valor de la producción para cada producto a nivel subregional y regional, deben ser consideradas como resultado de las diferencias entre las tasas de crecimiento estatal, regional y nacional o de las diferencias entre las estructuras de producción de los estados, las regiones y el país. ${ }^{19}$

\section{LA DISTRIBUCION}

Definir las unidades de análisis espacial constituye la condición previa en la tarea de definir una estructura agrícola fronteriza. Con este objeto, se realiza un corte territorial con base en las unidades político-administrativas constituidas por los seis estados fronterizos del norte del país, mismos que funcionan como unidades mínimas de análisis (Baja California, Sonora, Chihuahua, Coahuila, Nuevo León y Tamaulipas.

Con base en este criterio se utilizan dos niveles de agregación territorial. En primer lugar el interregional, en el cual la región fronteriza norte se considera como un todo que se compara con el resto del país. En segundo lugar el intrarregional, en el cual los estados fronterizos se analizan uno por uno, utilizando como estándar a la región fronteriza constituida por los seis. Estas unidades de análisis se densifican en términos de variables con respecto a la superficie cosechada y su valor.

\section{Interregional.}

Utilizando como instrumento de análisis los cocientes de localización tanto para superficie cosechada como para valor de la producción, se pudo contar con índices de relación de lo que hemos llamado región fronteriza, con el resto del país. Este cálculo por el grado de desagregación por producto arrojó extensas tablas, de las cuales recuperamos una tabla cuyos índices superiores a la unidad nos permiten apreciar las características de la especialización de la región con respecto al país en términos de productos, ya sea con respecto a la superficie cosechada, ya sea por su valor.

Con base en los resultados obtenidos, se puede distinguir una serie de productos que dan lugar a agrupamientos con respecto a la función predominante de cada uno de los productos principales.

En el primer grupo, constituido por los granos, se observan índices altos para la avena en grano, garbanzo para consumo humano, maíz palomero, sorgo en grano y trigo. Estos productos dentro de la producción de granos, son aquéllos que con excepción del trigo (durante varios años de exportación), benen como característica de ser en su mayoría de exportación.

19 Thirwall AP. "Proper distribution of the industry", Oxford Economic Papers, vol. 19, pp. 46-58 
Un segundo grupo lo constituyen las legumbres y hortalizas frescas. mismas que de una manera general constituyen uno de los rubros de exportación importantes del país desde finales de la década de los sesentas. Este de sarrollo se sitúa dentro de una estrategia más general a la que el país se integra rápidamente, exportando grandes cantidades de vegetales y frutas frescas. Estados Unidos incrementó sus importaciones de estos productos procedertes de México, de 36 millones de dólares en 1964 a más de 100 millones en 1969 y hasta 176 millones en 1973, haciendo que la exportación de estos bienes constituyera el $10 \%$ de todas las transacciones comerciales entre México y los demás países. 20 A esta estrategia la región fronteriza se integra de una manera paulatina al perder sus ventajas comparativas como productora de granos a nivel mundial. Esto hace que cada vez más, sobre todo en los distritos de riego fronterizos, se produzca y diversifique la siembra de hortalizas $y$ legumbres frescas destinadas al mercado externo. Como prueba de ello, el anexo I deja ver el comportamiento errático por producto de estos bienes, pero constante como grupo.

El tecer grupo de productos está constituido por los forrajes. Esta especialización de la región no es aleatoria, sino que más bien responde a la estructura agropecuaria regional, que históricamente aparece como una de las mayores productoras y exportadoras de carnes de bovino en el país. In tegrada en esta actividad pecuaria, la producción de forrajes es importante, arrojando índices importantes para la producción de avena, cebada, sorgo y trigo forrajero.

El cuarto grupo está constituido por las oleaginosas, entre las cuales destacan la aceituna, prácticamente concentrada en la región, y aquellos productos con precios elevados en el mercado mundial, como son el ajonjolí, la semilla de algodón, cártamo, girasol y sopa, debiéndose destacar el uso ganadero que en ocasiones se da a estos productos.

El quinto grupo, conformado por cítricos y frutas, muestra en nuestro anexo I la especialización regional, principalmente en todas aquéllas de alto valor, como son la manzana, uva, nuez de castilla y almendra, así como una especialización regional en la producción de cítricos.

Por último, por el valor que tiene y la importancia de la superficie cosechada en la región, destaca el algodón. Para 1981 este producto concentraba en la región el $75 \%$ del total de la superficie sembrada de él en el país, siendo un producto orientado casi en su totalidad hacia la exportación.

Estos agrupamientos nos permiten distinguir una cierta relación con respecto a las exportaciones de los bienes agropecuarios. En efecto, derivando

20 NACLA, Harvest of anger: agro-imperialism in Mexico's Northwest. Lat in American and Empire Report 10, No. 6(1976), p.11, en: De Janvry A., op. cit. p. 179. 
una tabla porcentual del anexo 2, que presentamos en el cuadro I, estamos en posibilidad de establecer una comparación entre la estructura de la producción regional por productos y la estructura de la exportación agrícola y ganadera por grupos de productos.

De esta relación podemos destacar el predominio de las hortalizas y legumbres frescas, la exportación de carne de bovino en pie y congelado, y el algodón. Es evidente, con respecto a los dos últimos productos dominantes, la tradición que tiene la región como productora, resultando un poco menos evidente su importancia como productora de hortalizas. Sin embargo, valdría en este sentido señalar la importancia creciente que tiene la participación de los estados fronterizos en el programa de siembra para la exportación, coordinado simultáneamente por la SARH y la UNPH.21

Intrarregional.

Utilizando el mismo método de análisis cuantitativo y variando las unidades de estudio, logramos establecer la especialización de cada estado por producto y con respecto a la región fronteriza.

CUADRO 1. Porcentaje de la exportación de bienes agrícolas y ganado bovino. 1977-1984.

\begin{tabular}{|c|c|c|c|c|}
\hline & 1977 & 1978 & 1979 & $1984^{\circ}$ \\
\hline 1. Granos & 4,65 & 7.74 & 8.21 & 4.11 \\
\hline $\begin{array}{l}\text { 2. Legumbres y hortalizas } \\
\text { frescas }\end{array}$ & 34.79 & 23,95 & 28.59 & 28.23 \\
\hline $\begin{array}{l}\text { 3. Ganado vacuno en pie y } \\
\text { congelado }\end{array}$ & 18.55 & 23.83 & 11.48 & 7.90 \\
\hline 4. Oleagin osas & 1.27 & 2.21 & 7.72 & 3.44 \\
\hline 5. Citricos y frutas frescas & 4.17 & 6.20 & 7.80 & 5.76 \\
\hline $\begin{array}{l}\text { 6. Algodón y bienes agrícolas } \\
\text { industriales }\end{array}$ & 29.69 & 30,00 & 28.87 & 16.26 \\
\hline 7. Otros productos agrícolas & 6.84 & 5.97 & 7.30 & 34.29 \\
\hline
\end{tabular}

FUENTE: Anexo II para 1977 a 1979.

* Para 1984, los valores no son estrictamente comparables con los años anteriores, motivo por el que se utilizan valores relativos, Ver cuadro 10. Exportación de mercancías por actividad económica de origen, según tipo de bien. Comercio Exterior de México, vol. VII, No, 12 (1985) pp, 15-21.

21 Remitirse a los numerosos boletines por año y producto: Programa siembra exportación, DGEA, SARH. 
Baja California. Tradicionalmente, la entidad tiene una produccción de granos relativamente importante; sin embargo, en su producción éstos tienen un papel complementario. Trigo y cebada tienen en este contexto un papel estratégico; el primero oscila en sentido inverso a las fluctuaciones en el mercado mundial del algodón, mientras el segundo cubre una parte de la demanda estatal para la producción de cerveza. En su conjunto, durante el período de estudio, ambas ocuparon aproximadamente el $15 \%$ de la superficie cosechada.

Tres grupos de productos dominan la producción estatal, mostrando un comportamiento más dinámico. En primer lugar el algodón, que es el cultivo más importante del estado y cuya participación en valor a la producción agrícola estatal fue del $30.0 \%$ en 1981 ; en segundo lugar la producción de hortalizas, cuya dinámica mostró cambios sustanciales a lo largo del período. Fue así, que de $4.3 \%$ en la superficie cosechada en 1977 , pasó a $6.6 \%$, con un aumento sustancial en el valor que pasó a su vez del $16.6 \%$ al $21.2 \%$. Para la producción de este grupo de bienes se debe destacar su diversificación, 22 que de un total de seis productos que se producían en 1977 pasó a 25 en 1981.

Por último, la producción de forrajes muestra un comportamiento constante, que se conforma con base en la producción de alfalfa, cebada y sorgo.

Sonora. El estado tiene una especialización con respecto a la producción de granos, y durante muchos años fue exportador de cereales. Con respecto al período de nuestro estudio, se debe destacar que la producción de trigo y garbanzo para consumo humano en 1977 concentraba el $45.6 \%$ del total de la superficie cosechada.

Para 1981, la estructura de la producción de granos se vio sensiblemente modificada. Se redujo la producción de garbanzo para consumo humano atribuible a la contracción en el mercado mundial, hasta alcanzar únicamente el $1.0 \%$ del total de la superficie cosechada, emergiendo la producción de básicos como central en la estructura de la producción agrícola estatal. En esta dinámica el maíz ocupó para el último año el $8.0 \%$ de la superficie total y el $3.0 \%$ el frijol, que reflejan el efecto del SAM en la producción agrícola estatal.

El efecto que tiene este programa se destaca aún más cuando se analizan las modificaciones en términos de valor. Con respecto a esta variable, la parti-

22 Esta relación de ninguna manera está desligada del programa de "Hortalizas" del Distrito de Riego 14 que muestra un aumento en las hectáteas de labot para este programa. Asimismo, debe destacarse la expansión experimentada en el valle de San Quintín desde finales de la década de los setentas. Por ejemplo de 1977 a 1985 el incremento de superficies de riego para la producción de hortalizas de exportación se incrementó a una tasa media anual de $15,4 \%$, mientras que para el periodo de $1982-85$ la tasa fue de $19.0 \%$. SARH, Distrito de Riego 14, Subjefatura de Distrito Operación y Desarrollo, Mexical, B.C.. 
cipación de la producción de frijol y maíz fue respectivamente de $17.2 \%$ y $7.1 \%$. Estos porcentajes, sumados a la producción de trigo, que fue del $26.4 \%$ para ese año, hicieron que poco más de la mitad (50.7) de la producción agrícola del estado fuera de productos básicos orientados hacia el mercado interno.

Este comportamiento sugiere un efecto derivado de la elevada productividad de la agricultura sonorense y el efecto de la política de precios de estos bienes originados en el SAM. Esta última constituyó una de las acciones principales en su estrategia para lograr una autosuficiencia alimentaria del país. Medida de corto plazo, la política de precios de garantía para los básicos, llevó a que de 1980 a 1981 , se elevaran los precios del maíz, trigo y sorgo en un 28,18 , y $24.0 \%$ respectivamente. Adicionalmente, se incrementaron los créditos disponibles a tasas preferenciales en un tercio y se redujeron las primas de seguros en un tres por ciento. 23

Estas influencias sobre el sector agrícola estatal, llevaron a cambios en las participaciones de los otros productos. Es así, que las hortalizas se redujeron en términos de superficie y de valor, esta última, de $8.5 \%$ a $6.5 \%$. Experimentando, sin embargo, una diversificación, que hizo pasar de 8 productos importantes en 1977 a 20 en 1981 .

El algodón, otro de los productos importantes de la entidad, mantuvo una ocupación en superficie cercana al $15.0 \%$. Sin embargo, frente a la modificación inducida en los precios, se operó un ligero retroceso con respecto al valor que pasó de $29.4 \%$ a $22.6 \%$.

Chihuahua. El estado es muy extenso y posee una proporción muy importante de tierras de temporal, factor que es determinante en la conformación de su estructura de producción agrícola. Se divide su producción entre básicos que se siembran sobre tierras de temporal y que se orientan principalmente en el mercado interno, y productos sembrados sobre superficies de riego, entre los cuales se encuentran las hortalizas y legumbres frescas, parte de forrajes, de oleaginosas y de frutales.

Su producción de básicos es desde siempre una de las más importantes de la región fronteriza, concentrándose sobre superficies de temporal. Es así, que el maíz, frijol y la papa que se encuentran entre sus productos principales, se cosecharon durante el período en un $90.0 \%$ sobre este tipo de tierras.

En el segundo grupo de productos, es pertinente señalar la combinación de las superficies de producción, entre temporal y de riego. Tal es el caso de

23 Bailey J.J., y J.E. Link, State craft and agriculture in Mexico, 1980-1982: Damestic and foreign policy. Working papers in U.S. -Mexican Studies, 23. UCSD, 1981, pp.31. 
los forrajes destinados al consumo de la importante población bovina de la entidad. La alfalfa, maíz y sorgo forrajero se producen de esta manera sobre las áreas de riego. Mientras, la avena forrajera, una de las producciones más importantes de la región se realiza sobre tierras de temporal.

De una manera diferente, se realiza la producción de hortalizas, entre las que destacan la cebolla, chile, col, etc., que se realizan totalmente sobre áreas de riego. Siendo el mismo caso, para frutales, como el durazno, la nuez y la manzana (una parte relativamente baja de ésta se produce sobre superficies de temporal).

Coahuila. La relativa proporcionalidad del estado entre superficies de riego y de temporal, tiende a matizar en la entidad la diferencia entre la producción de básicos en superficies de temporal y de productos de alto valor y de exportación en las superficies de riego. Con respecto a los primeros, los valores que arrojan los coeficientes de localización, nos permiten detectar comportamiento muy errático de los mismos. Sin embargo, profundizando sobre el comportamiento de su producción, se detectan modificaciones imputables a la operacionalización del SAM, mientras que, con respecto a los segundos, destaca una relativa consistencia de la producción de hortalizas, forrajes, algodón y los frutales.

Con relación a los básicos, la implementación del SAM trajo consigo que entre el año inicial del período y el final, se reorientaran superficies de temporal a la producción de maíz, frijol y trigo. Para superficies globales relativamente estables para la producción de los dos primeros productos, las superficies de temporal se incrementaron de $49.0 \%$ a $60.2 \%$ para el frijol, de $33.0 \%$ a $53.8 \%$ para el maíz, en tanto que para la producción de trigo el cambio proporcional fue de $18,7 \%$ a $48.1 \%$ de superficies de temporal para el último año.

La producción de hortalizas y legumbres frescas no mostró cambios sustanciales, realizándose casi en su totalidad sobre superficies irrigadas. En términos generales, el volumen y la diversificación no experimentaron notables cambios si se compara con los estados de Baja California y Sonora.

En la producción de forrajes, la producción estatal muestra una cierta similitud con respecto al estado de Chihuahua, con relación a la combinación de su producción entre tierras de temporal y riego. Es así que la alfalfa se produce totalmente en superficies de riego, mientras otro grupo de productos muestra proporciones muy diferentes; el $81.0 \%$ para la avena forrajera, el $81.0 \%$ para el sorgo forrajero y el $59.0 \%$ para la cebada forrajera.

El algodón, como uno de los principales productos del estado, concentró en promedio a lo largo del perfodo el $20.0 \%$ del total de la superficie co- 
sechada. Su participación fue aún más importante al aportar un promedio del $37.8 \%$, que destaca las condiciones relativamente favorables privando en el mercado mundial del producto, que coincide con nuestro período de estudio. Por lo que toca a la producción de frutales, se debe destacar la estabilidad en la superficie cosechada de los mismos durante el período, tendencia que destaca por la permanencia que muestran los cocientes de localización para productos como durazno, granada, higo, manzana, membrillo, nuez de castilla, piñón, tejocote y uva.

Nuevo León. En términos de calidad de las superficies cosechadas, la entidad experiment $\delta$ un ligero incremento con respecto a las superficies de riego, pasando de $47.4 \%$ a $51.7 \%$. De esta casi igualdad derivamos una especialización por productos, en dos grandes grupos, compuestos por la producción de granos básicos (frijol, maíz, trigo y sorgo) y de cítricos. En comparación con las modificaćiones experimentadas en los otros estados fronterizos como resultado del SAM, Nuevo León mostró pocas modificaciones imputables a este programa. Fue así que del total de la superficie cosechada en 1977, el $\mathbf{7 5 . 7 \%}$ lo era de básicos y el $22.0 \%$ de cítricos. Para 1981 estas proporciones se modificaron ligeramente, mientras los básicos constituyeron el $76.7 \%$, y los cítricos constituyeron el $16.5 \%$.

La entidad mostró también rasgos diferentes con relación a los otros estados fronterizos; en primer lugar, la utilización de proporciones importantes de riego en la producción de maíz, frijol y sorgo; en segundo lugar, hubo modificaciones poco sustanciales en la producción de estos últimos productos, imputables a los efectos del SAM.

Por último, derivado de la fuerte especialización en la producción agrícola de la entidad, cerca de un $10.0 \%$ del total de la superficie cosechada fue dedicada a los otros productos, entre los que destacan el alpiste, la cebada forrajera, sorgo para escoba, papa, aguacate, durazno y manzana.

Tamaulipas. El estado experimentó en el curso del último año del período un incremento en la superficie cosechada de 822612 has, incremento que correspondió casi en su totalidad a tierras de temporal ( 774715 has) en el cual tuvieron sus efectos los operativos derivados del SAM así como un buen año agrícola.

La producción de frijol, maíz, sorgo y trigo ocupó el $54.1 \%$ de la superficie total cosechada en el estado, incrementándose su participación en 1981, hasta llegar a $73.3 \%$.

Estos cambios dan cuenta de la gran inestabilidad de la producción agrícola de la entidad durante el período. En estas condiciones generales, destaca el importante papel que juega en la producción de legumbres y horta- 
lizas frescas de exportación el estado, y el potencial que tiene como proverdor del mercado del este de los Estados Unidos, destacándose como exportzdor de cebolla, ejote, ocra y jitomate.

La producción de oleaginosas, no es tan importante cuando se le relaciona en términos de superficie y valor de la producción, variables para las cuales durante el último año del período participó con un 6.0 y 2.0 por cierrto respectivamente, con una producción de cártamo, soya y ajonjolí. Junto a estos productos, destaca la producción de forrajes prácticamente circunscrita en los últimos años a los pastos, los cuales vieron aumentadas sus superficies durante la última parte del período, para constituir en 1981 el $35.0 \%$ de la superficie total cosechada en el estado para ese año, caracterizado por condiciones climatológicas muy favorables.

Por último, es pertinente señalar la importancia que tiene el estado en la producción de cítricos, los cuales se circunscriben casi totalmente a superficies de riego.

Del corto análisis que se acaba de hacer y del detalle que arrojan los valores de los coeficientes de localización (anexos 1 y 2 ) interregionales e intrarregionales, destacan las diferencias que tiene la zona fronteriza en términos de las superficies de producción y los efectos que éstas tienen sobre la diversificación y la orientación de la producción.

Como consecuencia de lo anterior, consideramos pertinente medir el grado de consistencia de la relación existente entre los valores obtenidos en términos de índices de localización con respecto a la superficie cosechada y el valor de la producción, para la región fronteriza y para cada uno de los estados fronterizos que manejamos como unidades de análisis.

Con base en los resultados obtenidos (cuadro II), se puede concluir que la relación para el conjunto de la región fronteriza es muy errática para el pe. ríodo de estudio, y por otra parte, muestra una consistencia muy alta cuandc se le analiza a nivel de entidad federativa.

De estos resultados derivamos la importancia que tiene la composición en términos de superficies irrigadas y de temporal a nivel estatal, como determinante, de manera simultánea, del grado de intensificación capitalista del suelo y de la naturaleza de la producción en términos del valor comercial de la misma. Ambos factores definen su interacción por el grado de especializa. ción de la producción entre cada uno de ellos con respecto a los productos de alto valor comercial, orientados hacia la exportación o hacia la transformación en otros sectores (como la industria o el subsector ganadero), y aqué. llos destinados al consumo regional y nacional que se producen en superficies de temporal. 
CUADRO II. Coeficientes de correlación $R$ derivados de los índices superiores a la unidad de la superficie cosechada y valor de la producción.

\begin{tabular}{lccccc}
\hline & $\mathbf{1 9 7 7}$ & $\mathbf{1 9 7 8}$ & $\mathbf{1 9 7 9}$ & $\mathbf{1 9 8 0}$ & $\mathbf{1 9 8 1}$ \\
\hline Región fronteriza & .9363 & .3122 & .6167 & .9292 & .5176 \\
Baja California & .8900 & .9613 & .8401 & .9003 & .9576 \\
Sonora & .9141 & .9221 & .9274 & .7644 & .7770 \\
Chihuahua & .9295 & .9645 & .9356 & .9463 & .9636 \\
Coahuila & .9409 & .9589 & .9402 & .9095 & .9267 \\
Nuevo León & .9040 & .8340 & .9277 & .9865 & .9460 \\
Tamaulipas & .9506 & .9719 & .9210 & .9293 & .9365 \\
\hline
\end{tabular}

FUENTE: Anexos 1 y 3

Siguiendo este criterio, el análisis cuantitativo y cualitativo confirma una tendencia según la cual los estados del noroeste (Baja California y Sonora) se especializan en cultivos de alto valor comercial y en gran medida orientados hacia el extranjero: granos (garbanzo para consumo humano), legumbres y hortalizas frescas, oleaginosas (ajonjoli) y cítricos, y forrajes para la engorda de ganado.

Los estados del norte y noreste (Chihuahua, Coahuila, Nuevo León y Tamaulipas) por su parte, se caracterizan por la producción de cultivos alimenticios de consumo regional y nacional en las áreas de temporal que son mayoritarias, con una producción de alto valor comercial que se concentra en los distritos de riego, orientada una parte hacia la exportación principalmente de algodón, hortalizas y la producción de forrajes para la engorda de ganado.

\section{LA NATURALEZA DE LA PRODUCCION}

La política económica con respecto a la agricultura mexicana en lo que va de la mayor parte del siglo XX, podría sintetizarse en dos grandes líneas de preocupación; la primera, en el incremento de la producción y la exportación; la segunda, derivada de una necesidad social en el sentido de elevar las condiciones de vida de la población rural.

Ambos objetivos siendo de una manera general complementarios, tienen en la práctica una alternancia que hace emerger las condiciones específicas del sector en un momento dado, así como el papel estratégico que juega éste en el marco de las relaciones políticas y económicas en el cual se articulan las relaciones externas e internas. 
La competencia relativa que se da en el tiempo y el espacio, con relación a las orientaciones de la política agrícola dictadas en el curso de los últimos años, deja ver el profundo desbalance en que se desarrolló el sector que sirvió de soporte para el proyecto nacional de desarrollo, orientándose hacia el incremento de la productividad y de la exportación como fuente de divisas.

La búsqueda de este último objetivo, considerado durantè muchos años prioritario, se tradujo territorialmente en las grandes obras de irrigación que transformaron mucho el paisaje agrícola del norte del país. Al mismo tiempo, transformaron las funciones técnicas de producción de múltiples unidades, al instrumentar medios de capitalización y utilización de innovaciones tecnológicas.

Paralelamente a este proceso, en el país se gestó una transíormación de la demanda interna para los productos agropecuarios como resultado de las elevadas tasas de crecimiento de la población y el notable proceso de urbanización, que terminó a finales de los años setentas, por hacer presente el conflicto latente entre las importaciones crecientes de básicos y la exportación de legumbres y hortalizas frescas, insumos industriales (algodón, por ejemplo) y ganado bovino engordado en su mayoría en los estados fronterizos.

En este conflicto destacan el dominio y la persistencia de un criterio produccionista en la dirección de la política económica con respecto al sector, en detrimento de las condiciones de vida de una proporción importante de la población rural. Por otra parte, se hacen presentes las condiciones de integración del país en la organización de la nueva división internacional del trabajo agrícola sustentada en la producción de alimentos baratos y el desarrollo del capitalismo en la agricultura.

En este contexto, el horizonte temporal de nuestro estudio se sitúa en un punto en el que confluyen las tendencias presentes a nivel mundial, y en las que México se integra impulsando las exportaciones, mientras que en los dos últimos años del mismo (1980 y 1981) aparece una contratendencia favorecida por el SAM como instrumento para reconducir la producción al mercado interno, que da signos de un déficit creciente en la oferta de básicos en un momento en que el mercado externo da signos de contracción. Es este proceso combinado el que constituye el objeto de nuestro análisis, circunscrito especialmente a la región fronteriza del norte de México, y que juega un papel central en la confluencia de ambas tendencias por su potencialidad física y su organización económica. Esto quiere decir que, mientras las grandes extensiones del norte del país ofrecen una alternativa a reducir la dependencia de básicos del exterior, Ias condiciones de la organización económica de estas unidades de producción, sustentadas en grandes inversiones de capital privadas y sociales, limitan la producción que en ellas se realiza a productos 
de alto valor comercial y preferentemente hacia la exportación, o hacia e] mercado interno cuando las expectativas dan señales favorables.

A esta complejidad que sugieren las líneas precedentes, debemos agregar las fuertes fluctuaciones a que ha estado sujeto el sector agrícola y agropecuario entre 1970-1982 como lo atestigua la figura 1.24 Esta inestabilidad en la tendencia podría llevarnos a limitar nuestras indagaciones que se orientan a un análisis intrarregional y longitu dinal, que nos permitan derivar el efecto que sobre las unidades de estudio constituidas por los estados, tiene la producción de exportación directa e indirecta (forraje) y el mercado interno constituido con base en una dieta básica.

Con este fin, utilizando el nivel de agregación territorial que probó mayor consistencia, vamos a analizar a través de un modelo de cambio participativo los efectos de estos tres conceptos, por lo que procedemos a utilizar como medio de simplificación tres diferentes subclasificaciones de produc$\operatorname{tos} .25$

\section{Mercado externo.}

El endeudamiento externo constituye el punto clave en la necesidad permanente del país por cubrir su déficit de balanza de pagos a través de su producción agrícola de exportación, haciendo que de una manera sistemática, el país oriente la mayor parte de la producción del norte hacia la producción de cereales en un momento dado; así como la producción de materias primas, la producción de forrajes y de una manera más reciente como productor de legumbres y hortalizas para exportación. Es con respecto a esta parte del proceso de internacionalización de la producción agrícola fronteriza del norte que buscamos desarrollar dos tipos de análisis para las estructuras subrregionales de exportación directa e indirecta.

Exportación directa. 1980 marca el primer año en que aparece un déficit en la balanza comercial agropecuaria, misma que se atribuye a la caída de la producción en el país durante 1979, y a la elevación de las cotizaciones a nivel mundial de granos y oleaginosas.

Consideramos que el efecto de esta inflexión es importante debido a la naturaleza de la producción agrícola fronteriza, por lo que tratamos de medir su impacto para cada uno de los estados que conforman la región a través de la producción en valor. Los resultados del análisis global de cambio participativo por entidad, nos sirven para este fin y se reflejan en la figura 2 (valores en el anexo 4.2).

24 El valor de $\mathrm{R}^{2}$ para la tendencia de crecimiento del PIB teal en el sector agropecuario es de 0.3144. y la tendencia para la rama de la agricultura es de 0.4232 .

25 Ver la clasificación en párrafos anteriores, y el cuadro 1. 
-n primer lugar, habría que señalar el comportamiento diferencial que tienen por un lado Baja California, Chihuahua y Nuevo León, si se les compara con un segundo grupo constituido por los estados de Sonora, Coahuila v Tamaulipas. En el primer grupo la declinación del cambio se sucede simultzneamente y en el mismo sentido que se presenta a nivel nacional para el sector y la rama (ver figura 1). Para los otros estados, la declinación aparece coe un período de retardo.

Una vez hecha esta primera diferencia, debe destacarse la magnitud de las variaciones de este grupo de bienes, siendo Baja California, Nuevo León y Tamaulipas los que muestran una may or sensibilidad, mientras que para Chhuahua, Coahuila y Sonora el cambio es inferior.

Por último, debemos señalar que el nivel de los cambios en todos los casos está determinado por valores superiores en la composición, pudiendo concluir, que el estado más sensible al impacto del sector de exportaciones es el de Baja California, y no siendo ajenas a este hecho las fluctuaciones en el algodón y de la producción de hortalizas durante el período.

Exportación indirecta (forrajes). De una manera casi general, la producción de forrajes muestra una tendencia decreciente durante el período de estudio, siendo la excepción el estado de Tamaulipas, que muestra un importante crecimiento durante el último año, con respecto a la expansión de pastos, Este comportamiento no está alejado de la notable contracción de la demanda de carne de bovino en Estados Unidos y la reducción en los precios que esto conlleva, lo cual hizo que en 1981 únicamente se cubriera aproximadamente el $75.0 \%$ de la cuota de importación de carne procedente de México en Estados Unidos.

De una manera general, esto ha representado una contracción en el hato de ganado en los estados fronterizos y en la rama, bastante sensible a la coyuntura interna y externa, que ha incidido en un comportamiento bastante errático. Antes de 1982, la contracción en la demanda estadounidense por un lado, y el costo de operación producto del precio elevado de los insumos, contribuyeron para deprimir la actividad. Después de 1982, la elevación constante de los costos de operación (productos de la inflación interna) y la contracción del mercado interno y externo, aceleraron después de 1983 la matanza de ganado y descapitalización de la actividad.

Esta tendencia, que se remonta hasta finales de la década de los setentas, aparece muy clara en el conjunto de los estados fronterizos, que salvo en el caso de Tamaulipas muestra valores positivos en todo el período. 


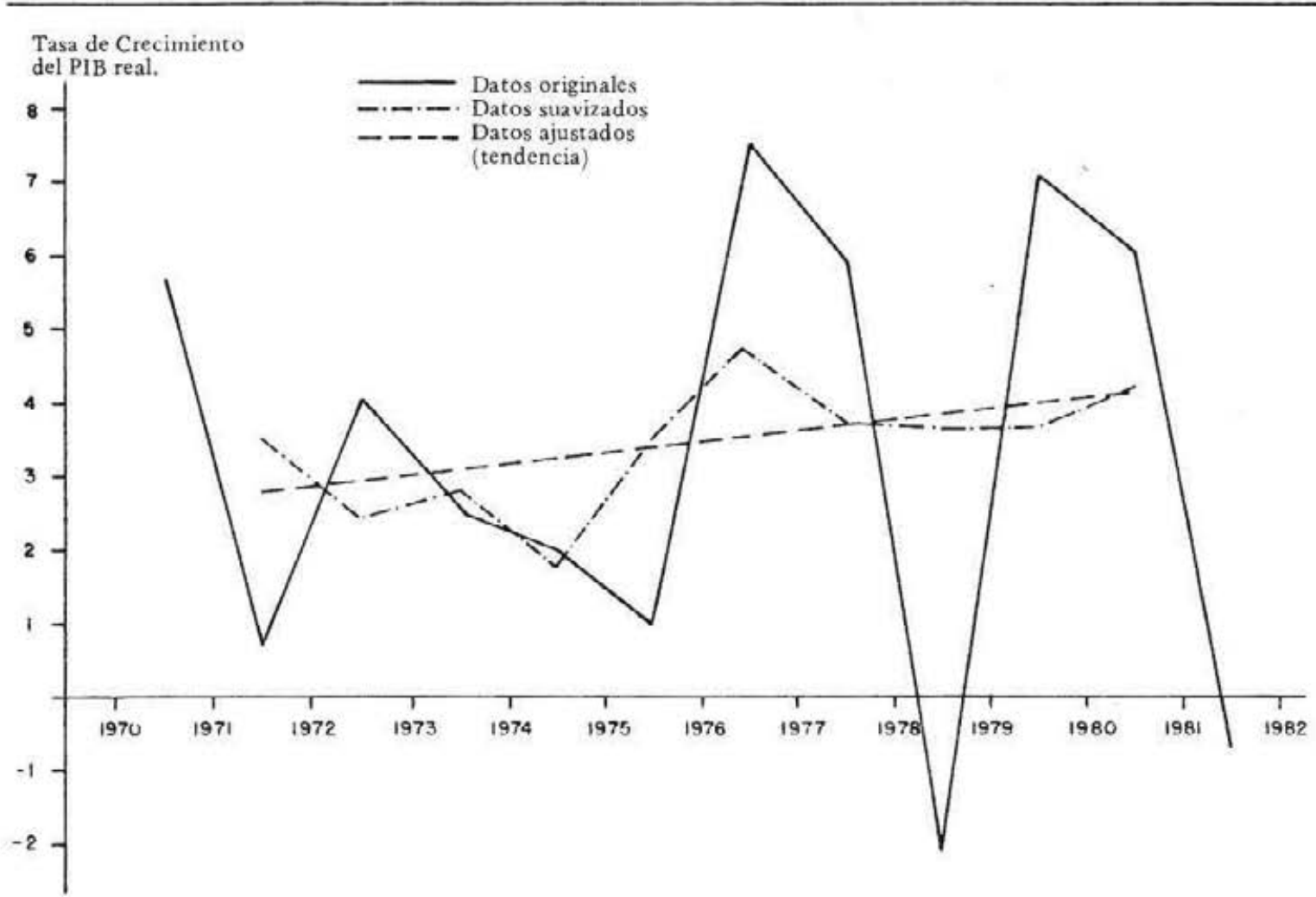

FIGURA 1-A. Comportamiento y tendencia de la tasa de crecimiento del PIB real en el sector agropecuario (1970-1981). 


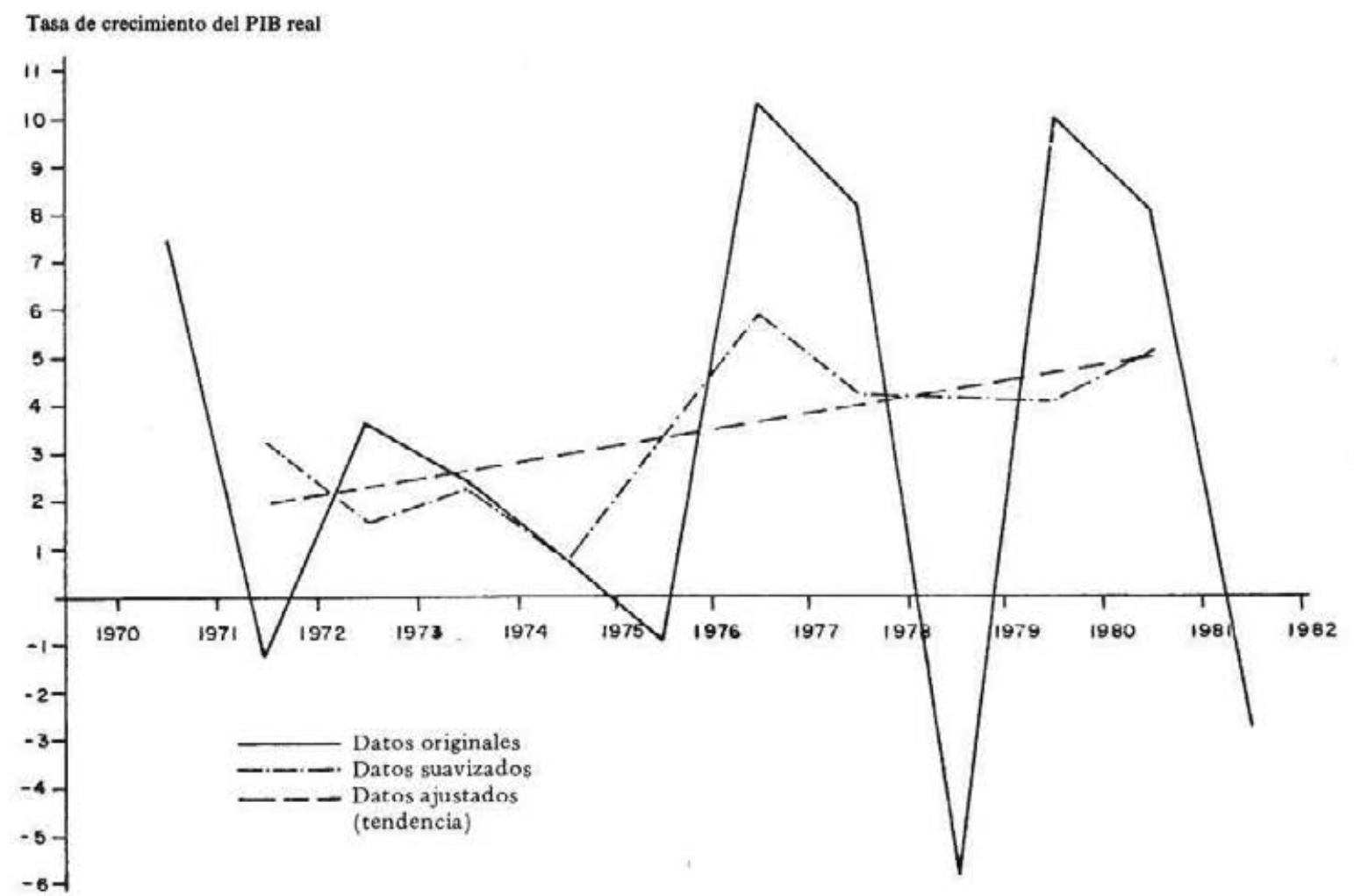

FUENTE: Sistema de Cuentas Nacionales, INEGI, SPP, 1984.

FIGURA 1-B. Comportamiento y tendencia de la tasa de crecimiento del PIB real en la rama agricultura (1970-1982). 


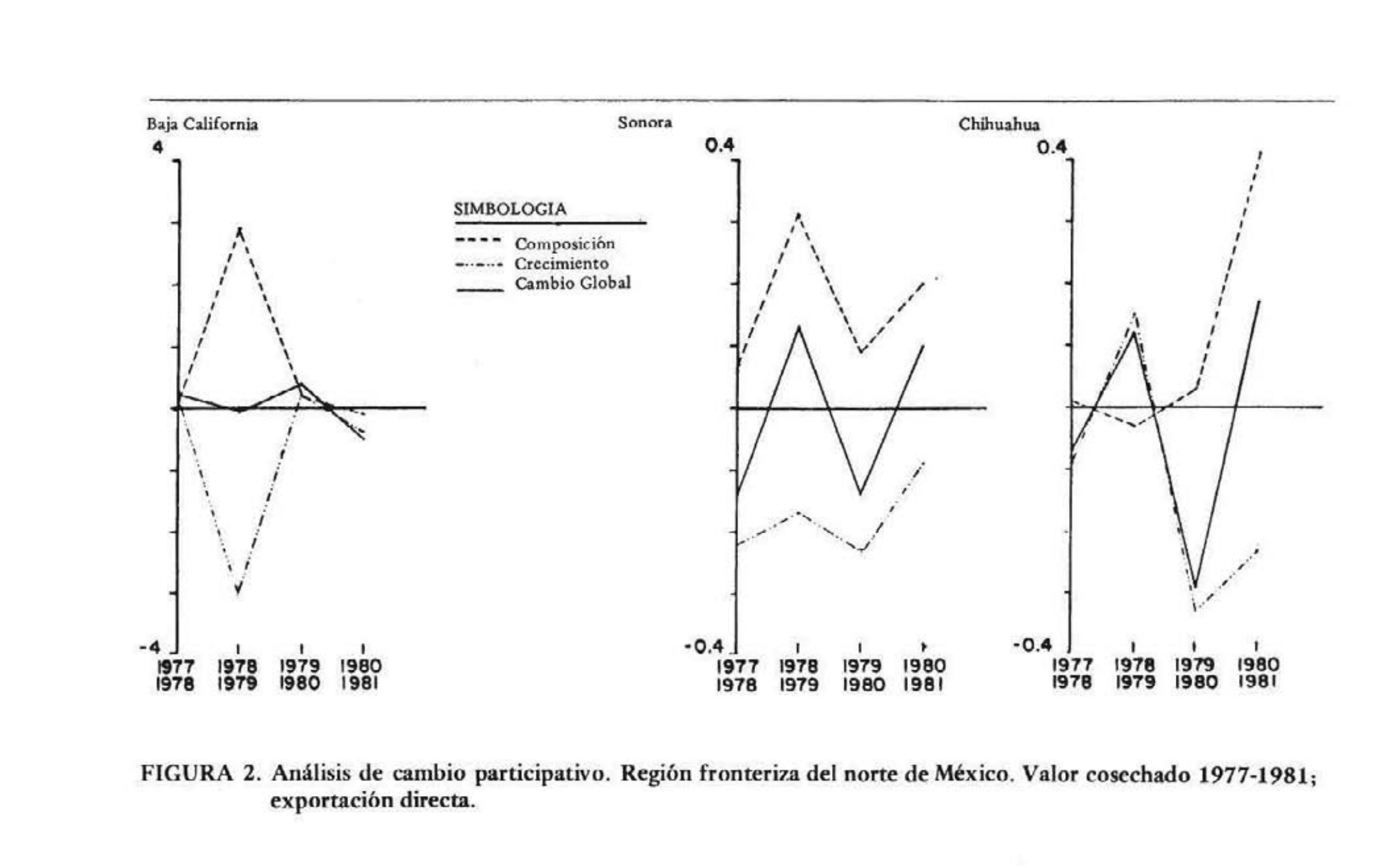


Figura 2 (Cont.)
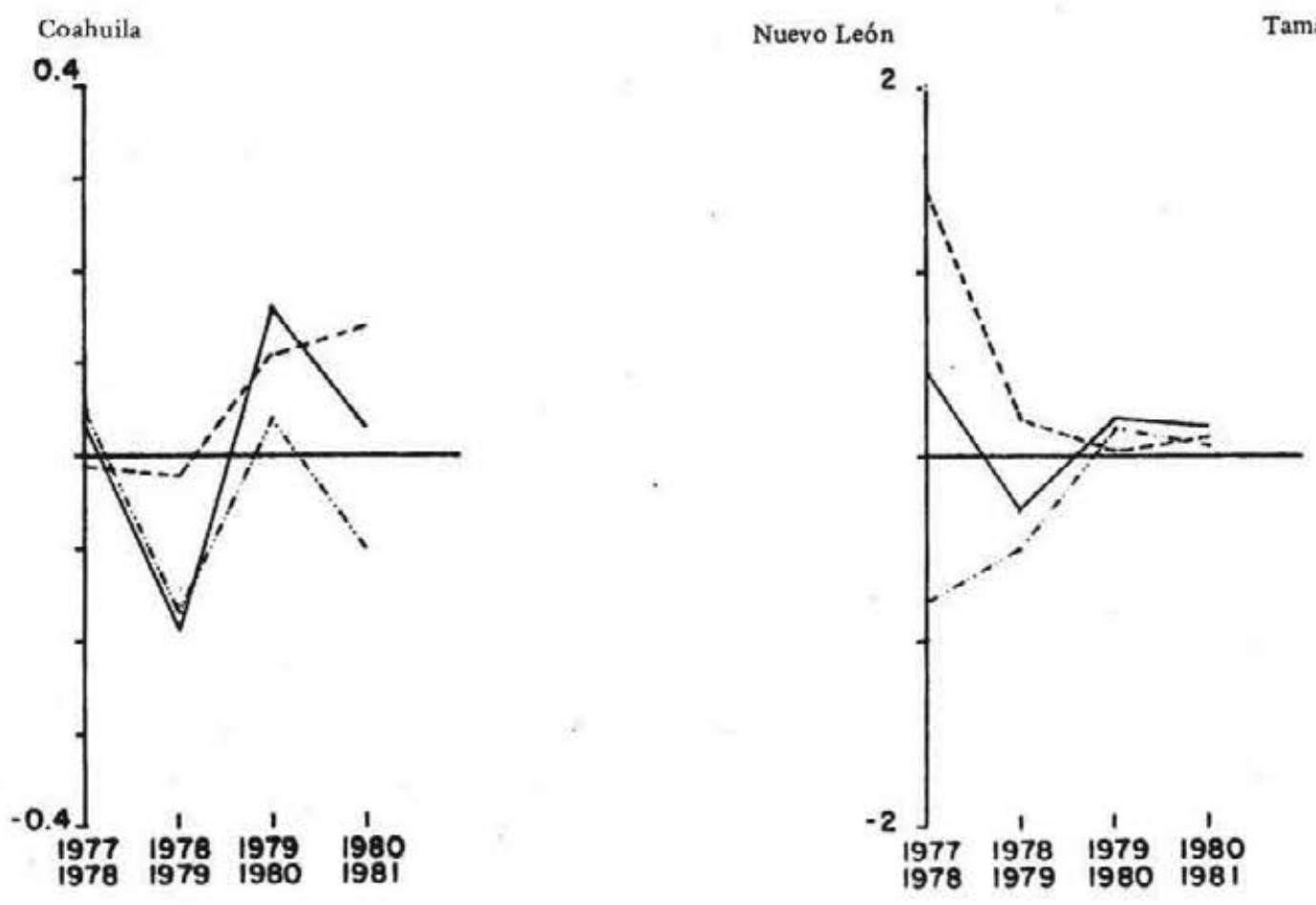

amaulipas

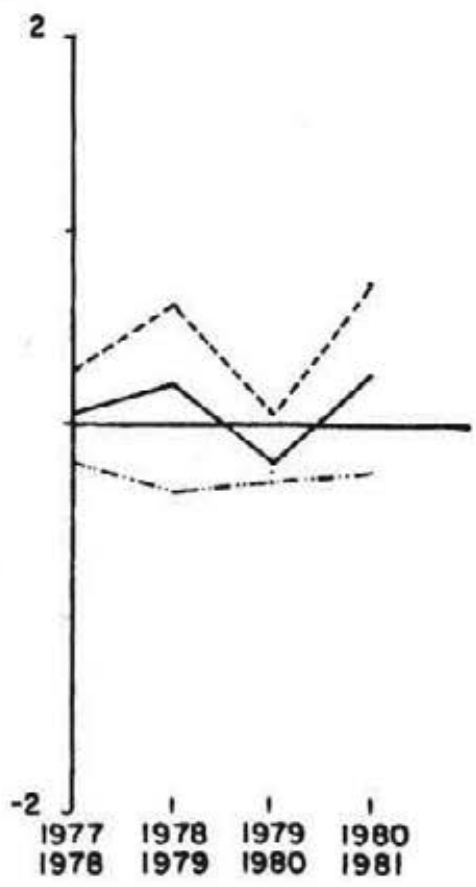



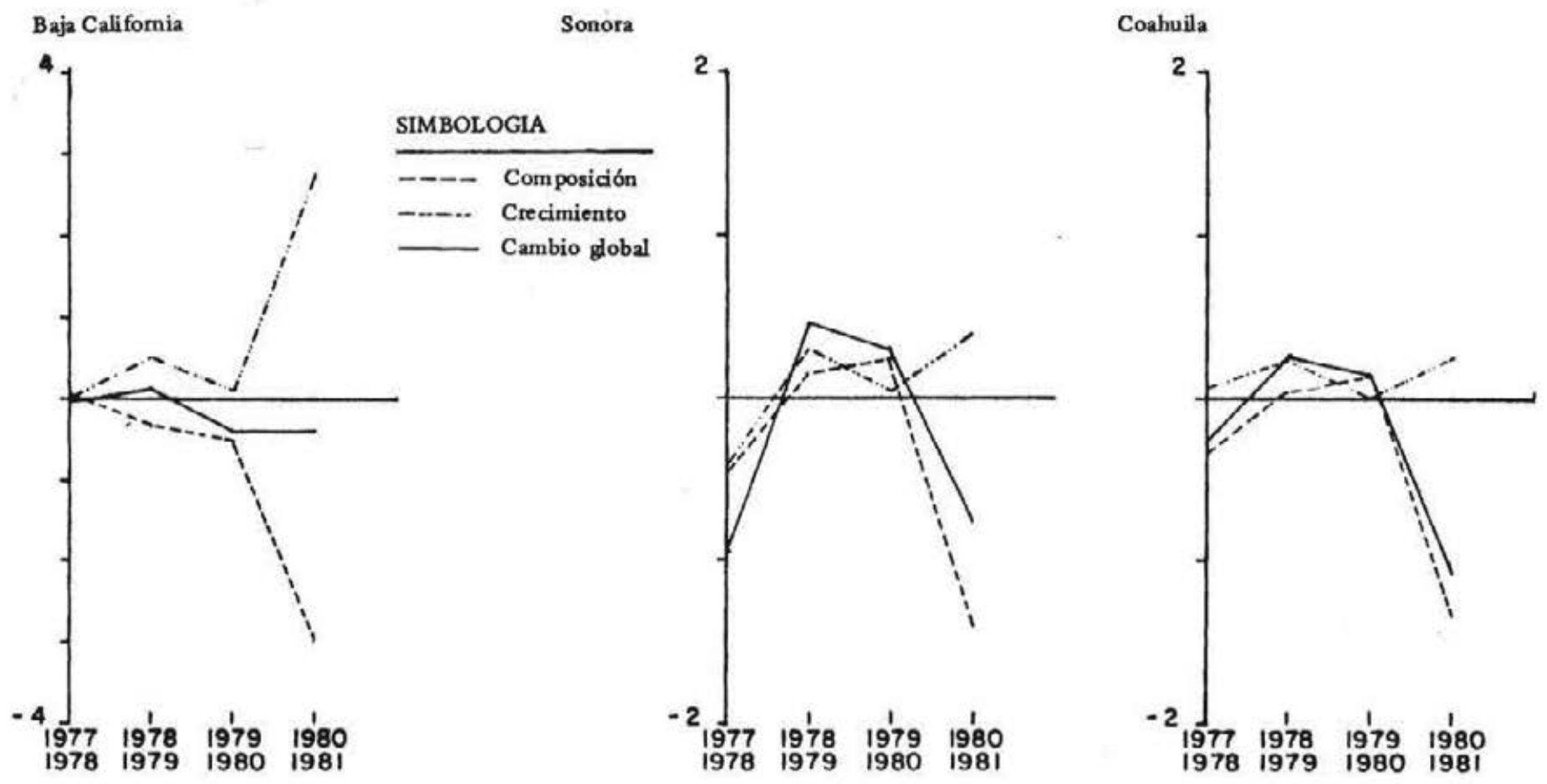

FíGURA 3. Análisis de cambio participativo. Región fronteriza del norte de México.Valor cosechado 1977-1981; exportación indirecta. (Forrajes). 


\section{Figura 3 (Cont.)}
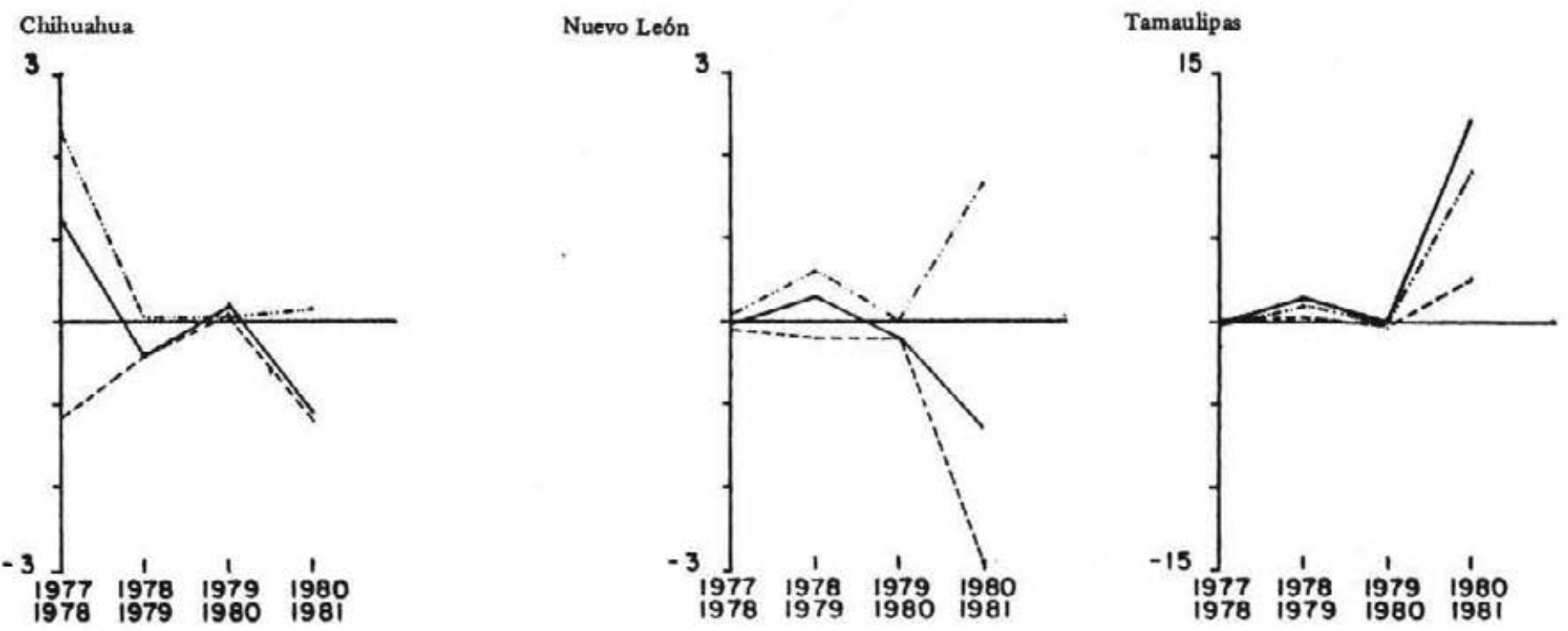


$$
A=p^{\prime}
$$




$$
\bar{W}_{k=t} \forall \mathbb{A}
$$




\section{Mercado interno.}

En el mes de marzo de 1980, el gobierno mexicano anuncia el Sistema Alimentario Mexicano (SAM) como marco dentro del cual se orientarán las acciones del sector público, a fin de que garanticen el mínimo nutricional para cada habitante. Con este objeto, se trazó una estrategia para desarrollar las áreas temporaleras del país, a través de mayores niveles de investigación, extensión, precios de garantía, subsidios, organización campesina y un fondo de riesgo compartido.

Desde el punto de vista financiero, el Estado se comprometió a utilizar parte de los recursos del petróleo para el desarrollo del agro, lo que llevó a que el Plan Global de Desarrollo anunciara durante el mismo año, un crecimiento en la inversión real programada de un promedio del $22.0 \%$ anual en el trienio 1980-1982; subiendo la participación agropecuaria de $20.3 \%$ en 1979 a $25.0 \%$ en 1982 .

Como resultado de toda esta serie de medidas, se fijó como meta lograr una autosuficiencia en maíz y frijol en 1982, y en 1985, de arroz, trigo, soya y oleaginosas. En la práctica, durante el año agrícola de 1980 creció en un $14.0 \%$, poco si se considera la fuerte contracción del año anterior,

Nuestro análisis muestra el impacto que esta serie de factores tuvo sobre la producción de básicos en cada una de las entidades federativas (figura 4). Utilizando como variable de análisis el valor de la producción, el efecto se agudiza, en virtud de que el efecto más sensible se encuentra al nivel de la política de precios de garantía y la liberación del control para algunos bienes agrícolas, lo que motivó la recuperación del sector agropecuario que alcanź su crecimiento mayor en el año de 1981, y recuperaciones posteriores en 1983 y 1985 .

A nivel estatal, estos efectos fueron más sensibles en el caso de los estados de Sonora, Chihuahua, Coahuila y Nuevo León, aunque muestran un retardo de un año en la producción de básicos, si nos guiamos por el cambio experimentado a nivel nacional. Esto podría sugerirnos que frente a un mercado internacional particularmente inestable, y a la baja para la mayoría de la producción agropecuaria mexicana, una buena parte, de la infraestructura agrícola del norte del país se reorientó hacia la producción de básicos, convertidos en muy atractivos por las políticas de precios imperando en ese momento. Este fenómeno es muy claro en el caso de Sonora, y fue señalado en la primera parte del trabajo.

Baja California y Tamaulipas muestran, por otra parte, un comportamiento inverso al de las otras entidades. La explicación puede encontrarse en la magnitud que experimentó el crecimiento de básicos en los otros estados 
y la poca participación proporcional en ambas entidades con respecto a esta producción. Esto nos llevaría a plantear dos causas: en primer lugar, una probable desvinculación de las estructuras productivas con respecto a la política de precios interna; en segundo lugar, una producción menor en 1981 con respecto a estos bienes, que durante 1980. En el primer caso se encuentra el estado de Baja California, fuertemente vinculado al mercado de exportación, mientras que en el segundo estaría el estado de Tamaulipas.

\section{CONCLUSION}

En las líneas precedentes hemos tratado de analizar en un período de cinco años, las características de la estructura de la producción agrícola de la región fronteriza del norte de México. Es muy probable que, para un sector tan inestable que se ha visto impactado por las turbulencias de la economía nacional y mundial, un estudio tan fragmentario se interprete como descripción innecesaria. Sin embargo, nuestro objetivo, trató de ir más allá de la pura descripción, buscando inferir, a través de un estu dio muy descriptivo, una explicación de carácter más general sobre los mecanismos intervinientes.

Esto significa que las transformaciones coyunturales que tienen efecto sobre cambios en las superficies y valor de la producción son el resultado de una serie de factores determinantes, con base en los cuales se estructura el sector, como son la inserción en el proceso de internacionalización de la producción agrícola y los efectos de ésta sobre la pérdida del control político y económico del sector por parte del Estado mexicano.

Ambos procesos constituyen el núcleo con base en el cual se deben analizar el desarrollo y las perspectivas de la agricultura fronteriza. El segundo de ellos, constituido como uno de los rasgos determinantes de la modernización del país, muestra un nivel elevado de intervención y control sobre el sector. A esto contribuyen tanto el aparato de legalización (SRA), como los de operación (SARH) y distribución (CONASUPO), llegando el Estado a participar inclusive como capitalista dentro del mismo (TABAMEX, FINASA, etc.). El primer proceso muestra las múltiples modalidades de la integración del territorio fronterizo, que va desde la importación directa, la inversión, la contratación, hasta llegar a la renta de las tierras, que se vuelve una práctica cada vez más frecuente.

Con base en esta relación, las condiciones particularmente difíciles por las que ha auravesado el sector de una manera general, conducen a que se desarrollen replanteamientos en términos de las condiciones de revalorización del capital, condiciones que, en el marco temporal de nuestro estudio, son de una manera general particularmente difíciles. Frente a una contracción en la demanda externa para los productos de exportación de las modernas unidades de producción del norte del país, antes de 1980 , son pobres las posibili- 
dades de realización que tienen los productores fronterizos en el mercado interno.

Después de 1980, la instauración del SAM, la reestructuración de los precios de garantía y la desaparición de los controles para otros, contribuyen a reorientar hacia el mercado interno a parte de la producción comercial de la región.

Este deslizamiento de la producción regional se complica después de 1982, al modificarse drásticamente los patrones de intercambio entre los dos países y la capacidad de la demanda en el mercado interno. Inflación galopante y costo del dinero en el país, aunados al deterioro de los precios de garantía, plantean una disyuntiva a los productores en la región, quienes se orientan en el sentido de contratar su cosecha o rentar sus tierras al exterior, donde el costo del dinero es más bajo, lo cual constituye una medida de protección frente a la desarticulación existente en los procesos de producción y consumo que se desarrollan entre los dos países.

Regionalmente, esta serie de condiciones que inciden en los diferenciales de comportamiento que emergen a través de nuestro análisis cuantitativo, muestran un nivel aceptable de consistencia cuando se le aborda a nivel de entidad federativa, a partir del cual es posible referirse en términos de grado de vinculación o desvinculación de la producción agrícola regional con respecto a la demanda nacional.

Es en este sentido que los estados utilizados como unidades de análisis permiten; por un lado, inferir de las características acerca de su producción o de la estructura de su estructura productiva (niveles de intensidad capitalista del sector), mientras que por otro, favorecen el conocimiento del grado de integración de la rama en cada una de las entidades, con respecto a las estructuras de producción y distribución norteamericana. En relación a esto, se debe destacar que los resultados de nuestro análisis en el estado de Baja California sugieren un alto grado de integración con respecto al exterior, lo cual se manifiesta también pero en menor proporción, en la agricultura de riego de las entidades de Tamaulipas y Nuevo León, lo que nos lleva a sugerir la importancia que tiene analizar en una secuencia similar los distritos de riego fronterizos. 
ANEXO I. Cocientes de localización por producto. Región fronteriza del norte de México. 1977-1981.

\begin{tabular}{|c|c|c|c|c|c|c|c|c|c|c|}
\hline & \multicolumn{2}{|c|}{1977} & \multicolumn{2}{|c|}{1978} & \multicolumn{2}{|c|}{1979} & \multicolumn{2}{|c|}{1980} & \multicolumn{2}{|c|}{1981} \\
\hline & 1 & 2 & 1 & 2 & 1 & 2 & 1. & 2 & 1 & 2 \\
\hline Avena en grano & 3.27 & 2.71 & 2.32 & 2.65 & 1,41 & 2.07 & - & 1.04 & 3.66 & 3.48 \\
\hline Cebada en grano & - & 1.27 & . & - & - & 1.09 & . & - & 1,02 & - \\
\hline Frijol & . & - & 4.63 & $\therefore$ & . & : & : & $\therefore$ & $\therefore$ & $\therefore$ \\
\hline Garbanzo p/c humano & 1.46 & 2.02 & 2.29 & 2.62 & 1.02 & 2.19 & 2.08 & 3.16 & 1.92 & 3.36 \\
\hline Maíz palomero & 5.15 & 8.73 & 4.31 & 4.27 & 4.56 & 4.24 & 4.50 & 4.71 & 4.47 & 5.01 \\
\hline Sorgo en grano & 1.53 & 1.11 & 1.93 & 1.09 & 2.10 & - & 2.02 & 1.71 & 2.01 & 2.25 \\
\hline Trigo & 3.06 & 2.85 & 2.68 & 2.54 & 2.56 & 2.54 & 2.67 & 2.91 & 2.54 & 2.74 \\
\hline Acciga & - & - & 4.09 & 13.38 & 1.19 & 24.76 & . & 6.85 & - & 15.22 \\
\hline Alcachofa & - & $=$ & - & . & . & 1.62 & 3.99 & 5.15 & - & - \\
\hline Betabcl & . & . & $\therefore$ & . & - & . & 1.31 & 1.56 & - & - \\
\hline Brócoli & - & - & 1.24 & 1.32 & - & 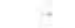 & $=$ & - & - & - \\
\hline Calabacita tierna & 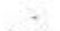 & 1.08 & 1.42 & - & $=$ & - & - & - & - & - \\
\hline Calabaza & 1.19 & 1.94 & - & & - & 1.08 & - & - & - & - \\
\hline Cebolla & + & 1.12 & 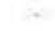 & 1.46 & 1.19 & 1.36 & 1.57 & 1.87 & 1.20 & 1.93 \\
\hline Col de Bruselas & - & - & 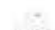 & & 2.14 & 3.48 & 3.50 & 4.31 & 4.43 & 4.79 \\
\hline Fspárrago & 1.42 & 1.36 & 1.67 & 1.77 & 2.30 & 2.08 & 2.20 & 2.12 & 2.16 & 1.87 \\
\hline Espinaca & & - & - & & & - & 1.37 & 1.70 & 3.47 & - \\
\hline Lechuga & & - & z. & 1.76 & $=$ & 1.03 & 1.18 & 1.21 & - & - \\
\hline Nabo & $\cdots$ & - & 2.64 & 1.80 & & 2.13 & 4.22 & 5.01 & - & 1.01 \\
\hline Ocra & 4.89 & 4.14 & 4.41 & 3.90 & 3.62 & 2.87 & 3.89 & 3.53 & - & 3.39 \\
\hline Rábano & $2+$ & - & 3.07 & 1.57 & & 1.90 & 1.56 & 2.30 & $=$ & 1.41 \\
\hline Rapini & - & . & - & ? & 5.00 & 4.60 & 4.56 & 4.73 & 4.49 & 4.88 \\
\hline Pepino & s. & - & $=$ & . & $=$ & $\because$ & 21.04 & 61.03 & - & - \\
\hline Papa & - & 1.35 & $=$ & 1.21 & $\therefore$ & 1.40 & - & - & $=$ & $=$ \\
\hline Alfalfa verde & 1.56 & 1.18 & 1.59 & 1.10 & 1.65 & 1.32 & 1.49 & 1.42 & 1.53 & 1.38 \\
\hline Alpiste & & - & 1.89 & 1.70 & 1.19 & 1.04 & 1.81 & 2.45 & 1.77 & 2.29 \\
\hline Avena forrajera & 3.42 & 2.00 & 3.19 & 3.08 & 3.42 & 1.66 & 3.05 & . & 2.83 & 1.70 \\
\hline Cebada forrajera & 3.07 & 3.33 & 2.61 & 2.91 & 3.06 & 3.21 & 3.14 & 2.49 & 2.44 & 2.17 \\
\hline Sorgo forrajero & 3.41 & 2.55 & 3.19 & 2.79 & 3.07 & 3.01 & 3.15 & 2.68 & 2.95 & 2.42 \\
\hline Trigo forrajero & - & .. & 3.03 & 4.17 & 3,44 & 3.09 & 3.93 & 2.60 & 4.52 & 4.88 \\
\hline Triticale forrajero & - & - & - & - & 5.00 & 5.00 & 4.24 & 4.52 & - & \\
\hline Aceitunas & 4.75 & 4.03 & 4.38 & 4.33 & 4.50 & 4.15 & 4.15 & 4.51 & 3.99 & 4.29 \\
\hline \multirow[t]{2}{*}{ Algodón semilla } & 3.09 & 2.68 & 2.92 & 2.98 & 3.17 & 3.02 & 3.11 & 3.35 & 3.16 & 3.70 \\
\hline & \multicolumn{2}{|c|}{1977} & \multicolumn{2}{|c|}{1978} & \multicolumn{2}{|c|}{1979} & \multicolumn{2}{|c|}{1980} & \multicolumn{2}{|c|}{1981} \\
\hline
\end{tabular}

\begin{tabular}{|c|c|c|c|c|c|c|c|c|c|c|}
\hline Ajonjoli & . & $=$ & - & $\bullet$ & $1: 53$ & 1,76 & - & 1.59 & - & $\cdot$ \\
\hline Cacahuate & + & 1.25 & + & 2.17 & - & - & $\cdot$ & - & - & 1.14 \\
\hline Cirramo & 2.01 & 1.86 & 2.42 & 2.18 & 2.21 & 2.04 & 2.27 & 2,01 & 1.79 & 2.08 \\
\hline Girasol & 2.23 & 2.46 & 1.10 & 1.47 & 1.73 & 1.22 & 1.40 & 1.28 & . & - \\
\hline Linaya & $2 \times 5$ & 2.85 & 2.06 & 3,06 & 1.98 & 4.10 & 1.32 & 3.65 & 2.08 & 3.14 \\
\hline Soya & 2.41 & 1.51 & 3.05 & 2.55 & 2.48 & 2.02 & 2,18 & 2.52 & 1.91 & 1.99 \\
\hline Algodón pluma & 3.09 & 2.70 & 2.92 & 2.84 & 3.17 & 3.02 & 3.11 & 3.42 & 3.16 & 3.46 \\
\hline Lupulo & 5.15 & 6.77 & 4.83 & 6.28 & 5.01 & 10.70 & + & - & • & , \\
\hline Sargo p/escols & 3.15 & 2,67 & 3.14 & 2.40 & 2.80 & 2.22 & 3.06 & 2.51 & 3.05 & 3.39 \\
\hline Plátano & 4.66 & 3.49 & 1.88 & 1.94 & 5.01 & 4.59 & + & - & . & . \\
\hline Mandarina & . & . & 2.56 & 1.70 & 2,06 & 2.97 & •. & 1.85 & 1.29 & 1.98 \\
\hline Naranja & 2.15 & 2.04 & 2.02 & 2.25 & 1.65 & 1.61 & 1.43 & 1.21 & 1.36 & 1.41 \\
\hline Toronja & 3.73 & 3.10 & 2.19 & 2.63 & 1.42 & 2.26 & - & + & - & + \\
\hline Algarroluo & 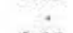 & $\therefore$ & $\cdot$ & 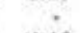 & 5.01 & 5.69 & +.56 & 6.52 & 4.49 & 5.38 \\
\hline Almendra & 3.49 & 4.33 & 4.74 & 4.45 & 4.77 & 4.25 & 4.23 & 4,42 & 4,22 & $\cdot$ \\
\hline Cercra & - & $=$ & - & $=$ & 5.01 & +46 & 412 & 4.68 & 402 & 480 \\
\hline Chabacano & 1.84 & 1.76 & 144 & 1.09 & 1.14 & - & - & , & - & * \\
\hline Dátil & 2.78 & 2.25 & 1.98 & 2.80 & 1.14 & 1.76 & - & 2.52 & 1.67 & 3.51 \\
\hline Manzana & 275 & 2.58 & 2,87 & 2.39 & 2.88 & $2 . \mathrm{kg}$ & 2.72 & 2.95 & 2.62 & 2.73 \\
\hline Membrillo & 1.16 & 1.54 & 1.18 & - & 22.77 & 20.26 & 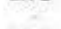 & - & 1.02 & - \\
\hline Nuer de Castilla & 98.93 & 27.47 & +01 & 116.81 & 3.19 & 2.17 & 3.93 & 3.16 & 3.88 & $3,+1$ \\
\hline Uva & 2.55 & 2.64 & 2.21 & 2.74 & 3.17 & 2.60 & 2,60 & 2.48 & 2.69 & 3,05 \\
\hline Dura/no & 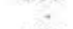 & - & 1.17 & 1.02 & 1.62 & $\because$ & 1.31 & - & - & \\
\hline Varios & 1.36 & 2.69 & 2.12 & 2.46 & 2.96 & 1.49 & 1.74 & . & - & . \\
\hline
\end{tabular}

1.- Superficke consedueds 


\section{ANEXO II. Valor de la exportación para bienes agrícolas y ganadería'} 1977-1979.

1. Garbanzo

S. trigo

2. Berenjena

Chilc o pimiento fresco

Cebolla

Pepino

Tomate fresco

Brócoli

Ajo

3. Ganado vacuno en pie

Congelado

4. Semilla ajonjolí

Semilla cártamo

Almendra de ajonjoli

5. Toronja

Melón

Naranja

Sandía

Mandarina

Fresas

6. Algodón

Henequén

Sorgo $\mathrm{p} / \mathrm{escoba}$
605437

78153

31413

9329

52926

197755

4789754

731

31567

1697243

1029348

$$
\begin{array}{r}
41564 \\
385 \\
145566
\end{array}
$$

26842

213197

48363

89352

29829

117094

4124713

5544

.232885
1715977

59616

143992

8267

228188

820655

4097973

165

188928

3804529

1658021

277423

1

230961

69600

780890

52310

220043

81511

218205

6601245

4374

285085
1956068

99751

202971

38193

633426

1321598

4714201

485

246864

2743257

131853

1478443

2892

451361

116512

1051517

103375

343540

97246

241086

6927107

299599

1828914

7. Otros productos agrícolas

1006167

1368107

FUENTE: Anuario de Comercio Exterior, INEGL. SPP, Mtxico, 1980 y 1981.

1 A partir de 1980 la desagregación de la actividad económica de origen y grupos de productos corresponde a la Clasificación Industrial Intemacional Uniforme (CIIU), que no es compatible con el Catślogo Mexicano de Actividades Económicas (CMAE), utilizado hasta 1979. 


\section{ANEXO III.1 Cocientes de localización por producto. Estado de} Baja California. 1977-1981.

\begin{tabular}{|c|c|c|c|c|c|c|c|c|c|c|}
\hline \multirow[t]{2}{*}{ - } & \multicolumn{2}{|c|}{1977} & \multicolumn{2}{|c|}{1978} & \multicolumn{2}{|c|}{1979} & \multicolumn{2}{|c|}{1980} & \multicolumn{2}{|c|}{1981} \\
\hline & 1 & 2 & 1 & 2 & 1 & 2 & 1 & 2 & 1 & 2 \\
\hline Avena en grano & $\therefore$ & - & - & $\therefore$ & $\therefore$ & & 1.1 & .1 & $\therefore$ & $\therefore$ \\
\hline Cebada en grano & 9.0 & 5.0 & 9.7 & 6.2 & 0.4 & 5.0 & 9.4 & 4.2 & 12.4 & 4.6 \\
\hline $\mathrm{Haba}$ & $\therefore$ & $\therefore$ & $\therefore$ & $\cdot$ & 10.9 & .9 & $\therefore$ & $\cdot$ & 11.7 & 2.6 \\
\hline Trigo & 2.5 & 1.3 & 1.6 & .9 & 2.0 & 9 & 1.6 & .7 & 1.8 & .9 \\
\hline Acclga & $\therefore$ & $\therefore$ & $\therefore$ & + & 8.7 & .5 & 7.1 & .5 & $\therefore$ & $\therefore$ \\
\hline Ajo & 5.3 & 3.5 & 3.6 & 1.6 & 3.1 & 2.1 & 4.3 & 2.1 & 5.5 & 2.2 \\
\hline Alcachofa & $\cdot$ & - & $\cdot$ & $\cdot$ & 10.9 & 4.5 & 11.5 & 4.4 & $\therefore$ & $\therefore$ \\
\hline Apio & - & - & - & - & • & • & $\cdot$ & - & 5.8 & 4.3 \\
\hline Betabel & - & - & & . & - & - & 8.8 & 3.4 & 8.7 & 4.5 \\
\hline Brócoli & - & - & - & - & - & - & 1.8 & 2.5 & 14.8 & 8.0 \\
\hline Calabacita tierna & $\cdot$ & - & - & $\cdot$ & $\cdot$ & - & $\therefore$ & - & 2.6 & 2.7 \\
\hline Calabaza & - & - & $\cdot$ & $\cdot$ & - & - & 1.5 & 2.7 & 14.9 & 7.7 \\
\hline Cebolla & - & - & 1.8 & 1.1 & 3.1 & 1.5 & 2.6 & .9 & 4.5 & 9 \\
\hline Cilantro & - & - & - & - & 3.6 & 3.2 & 3.6 & 10 & 8.4 & 2.1 \\
\hline Coliflor & - & - & $\therefore$ & $\therefore$ & 2.8 & 1.1 & 3.8 & 3.5 & 10.1 & 7.7 \\
\hline Col o repollo & - & - & 3.3 & 1.7 & 3.4 & 1.4 & 3.5 & 1.5 & 3.8 & 1.4 \\
\hline Chayote & - & $\therefore$ & - & $\therefore$ & - & - & - & - & 15.6 & 7.8 \\
\hline Chile seco & 10.4 & 6.6 & 6.3 & 4.0 & .5 & 3.8 & 3.7 & 3.1 & 10.3 & 6.7 \\
\hline Chile verde & $\cdot$ & •. & 1.0 & .6 & 1.2 & .8 & · & $\therefore$ & $\therefore$ & $\therefore$ \\
\hline Ejote & - & $\therefore$ & 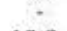 & - & .2 & 1.1 & .7 & 2.2 & 1.6 & 3.1 \\
\hline Espárrago & 12.0 & 7.2 & 10.9 & 6.6 & 9.0 & 5.9 & 9.1 & 43 & 10.5 & 6.1 \\
\hline Espinaca & • & $\cdot$ & $\cdot$ & $\therefore$ & $\therefore$ & $\cdot$ & 11.5 & 4.9 & 15.6 & 7.7 \\
\hline Lechuga & - & - & 4.1 & 3.9 & 6.2 & 4.0 & 8.9 & 3.8 & 10.5 & 4.8 \\
\hline Melón & 6.9 & 5.6 & 5.5 & 1.7 & 4.6 & 2.3 & 4.7 & 1.5 & 4.4 & .8 \\
\hline Nabo & - & - & - & - & - & • & 11.5 & 4.7 & 15.6 & 7.4 \\
\hline Nopalitos & - & - & - & - & • & - & - & - & 15.6 & 8.1 \\
\hline \multirow[t]{3}{*}{ Papa } & 1.3 & .8 & 1.8 & .7 & 1.8 & .9 & 2.4 & .8 & 2.1 & 1.4 \\
\hline & \multicolumn{2}{|c|}{1977} & \multicolumn{2}{|c|}{1978} & \multicolumn{2}{|c|}{1979} & \multicolumn{2}{|c|}{1980.} & \multicolumn{2}{|c|}{1981} \\
\hline & 1 & 2 & 1 & 2 & 1 & 2 & 1 & 2 & 1 & 2 \\
\hline Pepino & - & - & - & - & - & - & - & - & 1.8 & 1.5 \\
\hline Perejil & - & - & - & - & - & - & 11.5 & 4.7 & 15.6 & 7.3 \\
\hline Rábano & - & - & - & - & 9.8 & 6.0 & 9.4 & 4.5 & 14.6 & 8.1 \\
\hline Rapini & - & - & - & - & 10.9 . & 5.9 & 11.5 & 5.9 & 15.6 & 8.1 \\
\hline Sandía & 3.6 & 2.7 & 3.8 & 1.4 & 2.0 & 1.6 & 3.3 & 1.5 & 2.6 & 1.0 \\
\hline Tomate rojo & 4.1 & 4.9 & 4.6 & 3.4 & 3.7 & 4.1 & 5.7 & 3.6 & 8.1 & 9 \\
\hline Tomate verde & - & - & - & - & 1.2 & 1.4 & 1.9 & 1.4 & 5.2 & 3.9 \\
\hline Alfalfa verde & 3.0 & 2.0 & 2.8 & 1.7 & 2.5 & 1.3 & 3.1 & .9 & 2.7 & 8.8 \\
\hline Ccbada forrajera & - & - & 5.7 & 2.8 & 4.0 & 1.0 & 4.1 & 1.7 & 2.0 & 2 \\
\hline Pastos & 3.6 & 4.2 & 3.6 & 2.6 & 40 & 2.7 & 3.9 & 0 & $\cdot$ & - \\
\hline Remolacha forrajera & - & - & - & - & - & - & 9.9 & 2.0 & - & - \\
\hline Sorgo forrajero & 1.6 & 1.7 & 1.4 & 2.4 & 2.0 & 1.6 & 1.1 & .9 & 1.8 & 1.6 \\
\hline Trigo forrajero & - & - & - & - & 4.2 & 1.8 & $\cdot$ & - & - & - \\
\hline Accituna & 11.4 & 6.1 & 10.5 & 6.5 & 8.7 & 5.7 & 9.1 & 5.0 & 10.7 & 5.5 \\
\hline Ajonjolí & - & - & • & • & - & - & 1.9 & 1.8 & 2.2 & 2.1 \\
\hline Algodón semilla & 2.5 & 1.3 & 2.5 & 1.5 & 2.5 & 1.3 & 3.0 & 1.7 & 4.2 & 2.1 \\
\hline Algodón pluma & 2.5 & 1.3 & 2.5 & 1.6 & 2.5 & 1.5 & 3.0 & 1.5 & 4.2 & 1.8 \\
\hline Limón y lima & $\therefore$ & $\therefore$ & $\cdot$ & 1.4 & 1.1 & 1.7 & 1.0 & 1.7 & - & - \\
\hline Mandarina & 2.9 & 2.0 & - & - & - & - & - & - & - & $\cdot$ \\
\hline Algarrobo & $\therefore$ & - & - & - & 20.9 & 4.8 & 11.5 & 3.6 & 15.6 & 7.3 \\
\hline Nimendra & 12.0 & 6.9 & 10.9 & 6.6 & 10.9 & 6.2 & 11.5 & 5.1 & 15.6 & 8.2 \\
\hline C. de almendra & 3.9 & 6.0 & 1.1 & 2.4 & 1.9 & 4.9 & 1.5 & 2.8 & $\therefore$ & - \\
\hline Chabacano & 2.9 & 5.7 & 1.4 & 2.0 & 6.3 & 2.8 & 4.2 & 2.3 & 3.9 & .4 \\
\hline Dátil & 3.9 & .6 & 1.5 & .0 & 1.8 & 2.1 & 1.9 & 9 & 2.8 & 1.5 \\
\hline Higo & 3.0 & 3.0 & 1.0 & 1.6 & .9 & 2.8 & 1.1 & 2.6 & .8 & 2.8 \\
\hline Pera & 1.5 & 1.7 & .4 & 1.1 & $\cdot$ & $\therefore$ & $\therefore$ & - & 1.0 & 8 \\
\hline Uva & 2.8 & 1.5 & 3.2 & 2.4 & 1.8 & 1.3 & 1.8 & .7 & 2.4 & .4 \\
\hline
\end{tabular}

1 Superficie cosechada

2. Valur cosechado 
ANEXO III.2 Cocientes de localización por producto. Estado de Sonora. 1977-1981.

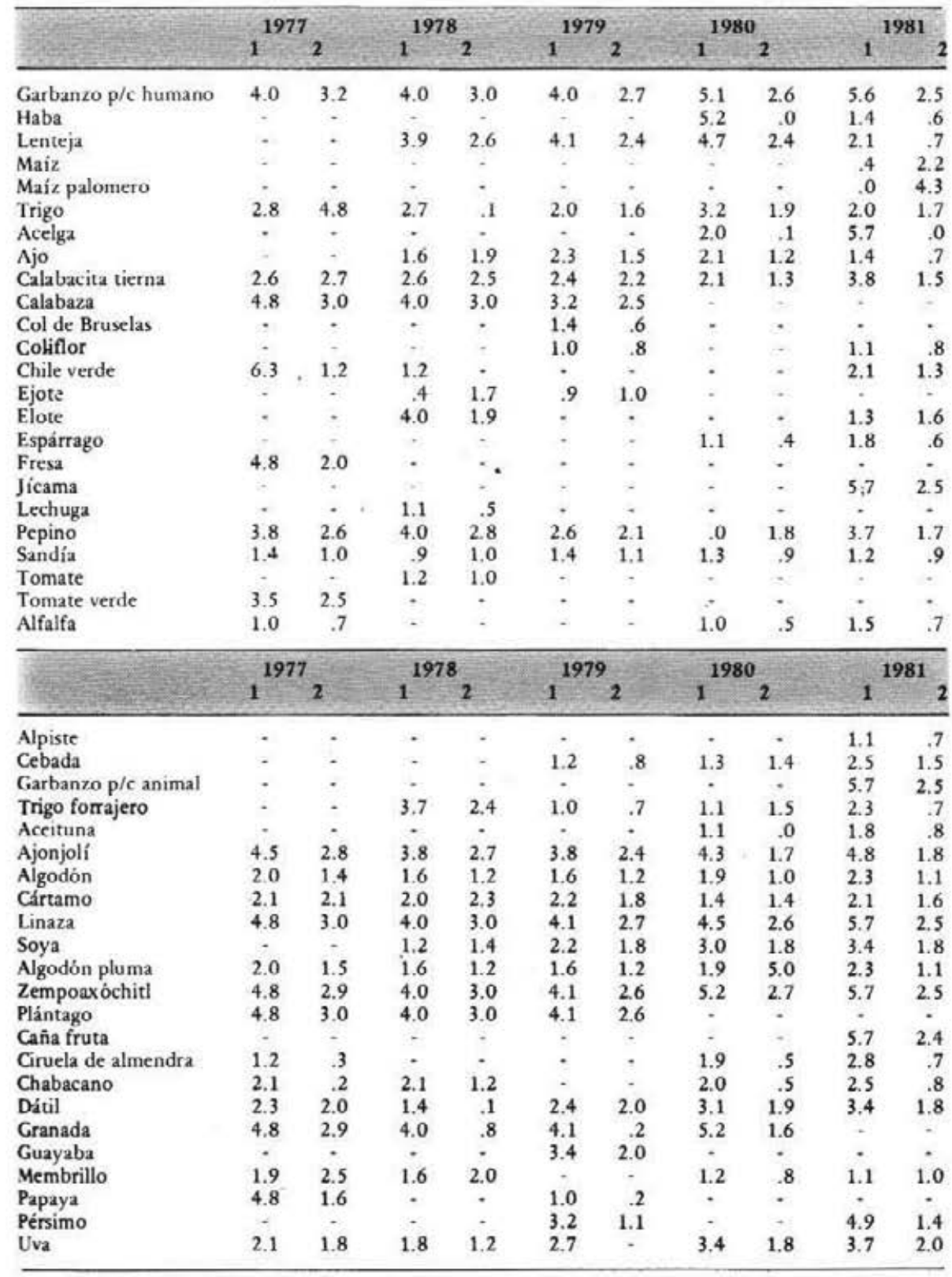

-Superficie cosechada

!. Valor coxschado 
ANEXO III.3 Cocientes de localización por producto. Estado de Chihuahua. 1977-1981.

\begin{tabular}{|c|c|c|c|c|c|c|c|c|c|c|}
\hline & \multicolumn{2}{|c|}{1977} & \multicolumn{2}{|c|}{1978} & \multicolumn{2}{|c|}{1979} & \multicolumn{2}{|c|}{1980} & \multicolumn{2}{|c|}{1981} \\
\hline & 1 & 2 & $1=$ & 2 & 1 & 2 & 1 & 2 & 1 & 2 \\
\hline Avena en grano & 4.4 & 5.7 & 5.3 & 5.4 & 3.6 & 4.4 & 2.9 & 4.3 & 4.1 & 3.5 \\
\hline Frijol & 3.7 & 3.9 & 3.8 & 3.5 & 3.0 & 3.4 & 3.2 & 3.4 & 2.4 & 2.0 \\
\hline Lenteja & - & - & - & - & - & $\cdot$ & - & $\cdot$ & 2.6 & 2.6 \\
\hline Maíz & 1.2 & 9 & 1.3 & .8 & 1.7 & .9 & - & - & 1.9 & .5 \\
\hline Sorgo en grano & - & . & 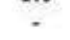 & - & 3 & 1.3 & - & - & - & - \\
\hline Trigo & - & - & - & - & .7 & .9 & - & - & - & $\cdot$ \\
\hline Ajo & - & - & - & - & - & - & - & - & 1.3 & 1.3 \\
\hline Camote & 4.6 & 5.8 & 5.5 & 5.5 & 3.9 & 5.2 & 4.7 & 5.1 & 4.1 & 3.5 \\
\hline Cebolla & 2.5 & 4.4 & 1.8 & 2.7 & 1.5 & 2.0 & 1.4 & 1.4 & 1.3 & .8 \\
\hline Col o repollo & 2.0 & 2.4 & 1.6 & 2.8 & - & - & 1.3 & 1.0 & 1.0 & 1.1 \\
\hline Chile seco & - & - & 1.4 & 1.7 & 3.8 & 1.0 & 2.5 & 1.1 & 1.3 & .5 \\
\hline Chile verde & 2.5 & 2.9 & 2.0 & 1.8 & 1.9 & 3.4 & 2.9 & 2.8 & 2.0 & 1.3 \\
\hline Elote & 4.6 & 5.5 & $\cdot$ & $\cdot$ & $\cdot$ & $\cdot$ & $\cdot$ & $\cdot$ & - & - \\
\hline Papa & 2.7 & 3.9 & 2.3 & 1.9 & 2.0 & 2.4 & 1.5 & .9 &. & - \\
\hline Tomate verde & 1.0 & .8 & - & - & $\cdot$ & $\cdot$ & - & - & $\because$ & - \\
\hline Alfalfa & 1.5 & 1.7 & 1.8 & 1.9 & 1.4 & 1.8 & 1.7 & 1.9 & 1.3 & 1.0 \\
\hline Avena forrajera & 4.0 & 3.4 & 5.2 & 5.4 & 3.8 & 3.2 & 4.5 & 1.8 & 3.5 & 2.2 \\
\hline Maíz forrajero & 1.0 & 1.4 & 2.0 & 2.5 & 2.5 & 2.8 & 2.6 & 2.1 & 1.7 & 1.1 \\
\hline Remolacha forrajera & - & - & $\cdot$ & - & $\cdot$ & - & $\cdot$ & $\cdot$ & 2.4 & .2 \\
\hline \multirow[t]{3}{*}{ Sorgo forrajero } & $\cdot$ & 1.0 & $\cdot$ & - & - & $\cdot$ & - & $\cdot$ & $\cdot$ & $\cdot$ \\
\hline & \multicolumn{2}{|c|}{1977} & \multicolumn{2}{|c|}{1978} & \multicolumn{2}{|c|}{1979} & \multicolumn{2}{|c|}{1980} & \multicolumn{2}{|c|}{1981} \\
\hline & 1 & 2 & 1 & 2 & 1 & 2 & 1 & 2 & 1 & 2 \\
\hline Trigo forrajero & - & - & - & - & - & - & 2.7 & 1.8 & - & - \\
\hline Triticale forrajero & - & $\cdot$ & - & $\cdot$ & 4.2 & 5.0 & 4.9 & 4.2 & - & - \\
\hline Cacahuate & 4.1 & 5.4 & 4.0 & 4.3 & 3.7 & 4.7 & 4.6 & 4.8 & 3.7 & 3.3 \\
\hline Soya & 5 & 1.3 & .6 & 1.0 & - & - & 1.1 & 1.3 & 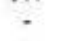 & - \\
\hline Lúpulo & 4.6 & 3.7 & 5.6 & 4.0 & 4.2 & 2.3 & $\cdot$ & 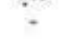 & - & * \\
\hline Sorgo p/escoba & - & - & 1.1 & 1.3 & - & - & - & - & - & - \\
\hline Cereza & - & - & $\cdot$ & $\cdot$ & 4.2 & 5.6 & 4.9 & 5.1 & 4.2 & 3.6 \\
\hline Ciruela de almendra & - & - & 2.4 & 1.8 & 1.4 & .6 & 1.2 & .6 & 1.4 & 1.5 \\
\hline Chabacano & 1.1 & 3 & 1.3 & 1.0 & 1.6 & 2.8 & 1.1 & 1.7 & 7 & 1.5 \\
\hline Durazno & 3.1 & 2.3 & 3.9 & 4.4 & 3.1 & 4.5 & 3.8 & 4.2 & 2.9 & 2.5 \\
\hline Granada & 1.0 & 3.4 & 1.3 & 3.6 & .7 & 1.2 & $\cdot$ & $\cdot$ & - & - \\
\hline Guayaba & 3.6 & 5.2 & 5.3 & 5.4 & - & $\cdot$ & $\cdot$ & $\cdot$ & $\cdot$ & $\cdot$ \\
\hline Manzana & 3.2 & 4.8 & 3.5 & 4.0 & 2.8 & 4.1 & 3.5 & 5.0 & 2.9 & 2.4 \\
\hline Membrillo & 2.2 & .5 & 1.8 & .3 & - & - & 3.6 & 1.6 & 3.0 & 1.5 \\
\hline Nectarina & - & - & - & - & 4.1 & 4.9 & 4.8 & 4.9 & 4.2 & 3.6 \\
\hline Nuez de Castilla & 1.3 & 3.2 & 1.7 & 2.8 & 2.6 & 2.9 & 2.2 & 1.5 & 1.7 & 1.4 \\
\hline Pera & 3.4 & 1.6 & 3.1 & 3.7 & 2.8 & 4.1 & 3.4 & 3.9 & 2.9 & 2.7 \\
\hline Perón & - & - & 5.6 & 5.2 & 4.2 & 5.1 & - & - & 4.2 & 3.4 \\
\hline Pérsimo & - & - & - & - & .8 & 3.2 & - & - & $\cdot$ & - \\
\hline Tejocote & - & - & 4.3 & $5.5^{\circ}$ & 4.2 & 5.6 & - & - & 4.2 & 3.6 \\
\hline
\end{tabular}

1. Superficie cosechada

2. Valor cosechado 
ANEXO III.4 Cocientes de localización por producto. Estado de Coahuila. 1977-1981.

\begin{tabular}{|c|c|c|c|c|c|c|c|c|c|c|}
\hline & \multicolumn{2}{|c|}{1977} & \multicolumn{2}{|c|}{1978} & \multicolumn{2}{|c|}{1979} & \multicolumn{2}{|c|}{1980} & \multicolumn{2}{|c|}{$1981=$} \\
\hline & 1 & 2 & 1 & 2 & 1 & 2 & 1 & 2 & 1 & 2 \\
\hline Avena en grano & - & - & - & . & 1.1 & 1.7 & 3.9 & .5 & - & - \\
\hline Cebada & 2.0 & .9 & - & - & 1.0 & .5 & - & $\cdot$ & $\cdot$ & - \\
\hline Frijol & 1.5 & 1.0 & $\therefore$ & $\cdot$ & $\cdot$ & $\cdot$ & $\cdot$ & - & $\cdot$ & $\therefore$ \\
\hline Maíz & $\cdot$ & $\cdot$ & 1.0 & .7 & - & - & - & - & 9 & 2.5 \\
\hline Trigo & - & - & - & - & 1.0 & .2 & - & - & 1.2 & .2 \\
\hline Ajo & 2.7 & 2.6 & - & - & - & - & - & - & $\cdot$ & - \\
\hline Betabel & 12.0 & 8.5 & 12.7 & 7.4 & 14.5 & 11.0 & 3.9 & 3.1 & 7.3 & 3.9 \\
\hline Camote & - & $\cdot$ & - & - & 1.1 & 6 & - & - & - & - \\
\hline Cilantro & 12.0 & 7.2 & 12.7 & 8.3 & 9.5 & 4.5 & 10.1 & 6.9 & 6.9 & 5.5 \\
\hline Coliflor & $\therefore$ & $\therefore$ & .9 & 1.4 & $\therefore$ & $\therefore$ & $\cdot$ & $\cdot$ & $\cdot$ & $\cdot$ \\
\hline Col o repollo & 3.2 & 3.2 & $\cdot$ & $\cdot$ & 2.0 & 2.9 & $\cdot$ & - & 2.1 & 3 \\
\hline Chile verde & $\cdot$ & - & - & $\cdot$ & 1.0 & .5 & - & - & - & - \\
\hline Lechuga & 6.0 & 6.2 & 2.2 & 1.3 & 1.2 & 1.6 & - & - & - & - \\
\hline Melon & $\because$ & - & 1.4 & 1.4 & 2.5 & 2.9 & 2.5 & 2.2 & 7.0 & 5.9 \\
\hline Nabo & $\cdot$ & - & . & 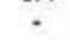 & 14.5 & 9.7 & 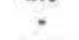 & 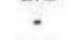 & $\cdot$ & - \\
\hline Papa & $\cdot$ & $\cdot$ & $\cdot$ & - & - & $\cdot$ & 1.8 & 1.7 & 1.5 & 1.9 \\
\hline Sandía & 1.6 & 1.6 & - & - & 1.0 & 1.1 & 1.7 & 1.6 & 4.1 & 3.2 \\
\hline Tomate verde & - & - & 6.9 & 5.3 & $2: 8$ & 5.6 & $\cdot$ & - & - & - \\
\hline Alfalfa & 1.7 & 1.5 & 1.8 & 2.0 & 2.1 & 2.1 & 2.8 & 1.9 & 2.7 & 1.6 \\
\hline \multirow[t]{3}{*}{ Alpiste } & 2.9 & 1.7 & 6.6 & 4.4 & 10.2 & 5.7 & 8.6 & 4.4 & 8.8 & 3.4 \\
\hline & \multicolumn{2}{|c|}{1977} & \multicolumn{2}{|c|}{1978} & \multicolumn{2}{|c|}{1979} & \multicolumn{2}{|c|}{1980} & \multicolumn{2}{|c|}{1981} \\
\hline & 1 & 2 & 1 & 2 & 1 & 2 & 1 & 2 & 1 & 2 \\
\hline Avena forrajera & 1.4 & 3.6 & - & $\cdot$ & 1.0 & 3.7 & .9 & 4.8 & 2.0 & 2.6 \\
\hline Ccbada forrajera & 9.9 & 5.7 & 2.9 & 1.7 & 2.2 & .7 & 2.2 & 5 & 4.9 & 1.2 \\
\hline Maíz forrajero & 9.4 & 7.6 & 4.1 & 3.0 & 2.7 & 2.5 & 4.5 & 3.6 & 6.5 & 4.2 \\
\hline Pastos & 4.2 & .4 & 3.7 & .8 & 2.0 & 1.5 & 1.9 & 2.1 & $\cdot$ & - \\
\hline Remolacha forrajera & $\cdot$ & $\cdot$ & $\cdot$ & $\cdot$ & $\cdot$ & $\cdot$ & $\cdot$ & $\cdot$ & 4.3 & .1 \\
\hline Algodón semilla & 2.3 & 2.3 & 2.6 & 2.1 & 2.7 & 2.0 & 3.0 & 1.7 & 2.6 & 1.4 \\
\hline Algodón pluma & 2.3 & 1.9 & 2.6 & 2.2 & 2.7 & 1.9 & 3.0 & 6 & 2.6 & 1.8 \\
\hline Barbasco & 4.4 & 5.6 & 3.1 & 3.7 & 4.6 & 6.2 & 3.7 & 4.9 & 4.2 & 3.5 \\
\hline Chabacano & $\cdot$ & $\cdot$ & $\cdot$ & - & $\cdot$ & - & - & $\cdot$ & 1.3 & .5 \\
\hline Dátil & 2.2 & 2.3 & 2.6 & 1,0 & 3.4 & 1.8 & 3.8 & 9 & 3.6 & .6 \\
\hline Durazno & - & - & - & $\because$ & 1.0 & .5 & 1.2 & .3 & 4.0 & .3 \\
\hline Granada & 8.9 & 3.8 & 8.4 & 3.4 & 11.2 & 8.6 & 13.5 & 9.0 & 13.5 & 6.5 \\
\hline Higo & 6.7 & 4.0 & 8.8 & 4.4 & 10.3 & 3.8 & 12.6 & 3.5 & 10.7 & 3.5 \\
\hline Manzana & 3.1 & 3 & 3.2 & 1.5 & 3.5 & 1.8 & - & - & 3.9 & 1.5 \\
\hline Membrillo & 1.1 & .2 & 1.7 & .4 & $\therefore$ & - & .4 & 1.1 & 1.1 & .5 \\
\hline Nuez de Castilla & 2.5 & 2.5 & 2.0 & 1.6 & 3.8 & 3.3 & 3.8 & 3.7 & 4.8 & 2.4 \\
\hline Piñón & 12.0 & 10.1 & 12.7 & 9.9 & 14.5 & 11.0 & 16.5 & 9.6 & 16.5 & 8. 8 \\
\hline Tejocote & 12.0 & 9.2 & 2.9 & 1 & - & - & - & $\cdot$ & - & - \\
\hline Uva & 3.3 & 1.8 & 2.6 & 2.0 & 2.0 & 1.3 & 2.5 & 1.5 & 2.6 & 1.2 \\
\hline
\end{tabular}

1. Superficie cosechada

2. Valor cosechado 
ANEXO III.5 Cocientes de localización por producto. Estado de Nuevo León. 1977-1981.

\begin{tabular}{|c|c|c|c|c|c|c|c|c|c|c|}
\hline & \multicolumn{2}{|c|}{1977} & \multicolumn{2}{|c|}{1978} & \multicolumn{2}{|c|}{1979} & \multicolumn{2}{|c|}{1980} & \multicolumn{2}{|c|}{1981} \\
\hline & 1 & 2 & 1 & 2 & 1 & 2 & 1 & 2 & 1 & 2 \\
\hline Arroz palay & - & - & 1.6 & 1.9 & - & - & - & - & - & - \\
\hline Cebada & - & - & - & - & - & - & 1.0 & .3 & - & - \\
\hline Frijol & .9 & 1.5 & - & - & 1.0 & .6 & $\cdot$ & - & - & $\cdot$ \\
\hline Maiz & 1.4 & 1.5 & 1.6 & 1.1 & 1.8 & .9 & 1.6 & .6 & 1.6 & 2.6 \\
\hline Sorgo en grano & 1.5 & 2.1 & 1.0 & 1.6 & 9 & 6.5 & 1.1 & 1.0 & 1.1 & .5 \\
\hline Trigo & - & - & - & $\therefore$ & - & - & - & - & 1.8 & .3 \\
\hline Acelga & $\cdot$ & - & 14,6 & 3.6 & - & - & - & $\cdot$ & $\cdot$ & $\cdot$ \\
\hline Ajo & 2.2 & 8 & 2.3 & .9 & - & - & $\cdot$ & - & - & - \\
\hline Apio & , & - & $\cdot$ & $\cdot$ & $\cdot$ & $\cdot$ & 9.5 & 4.1 & $\cdot$ & - \\
\hline Brócoli & - & . & - & & & & 1.5 & .8 & - & - \\
\hline Coliflor & $\because$ & $\cdot$ & $\cdot$ & $\cdot$ & 1.0 & 1.7 & 1.1 & 1.1 & - & $\cdot$ \\
\hline Col o repollo & 3.5 & 4.3 & 3.5 & 2.0 & 1.0 & 3 & 2.6 & 2.6 & 1.2 & 1.9 \\
\hline Elote & $\therefore$ & - & $\cdot$ & $\cdot$ & $\cdot$ & - & 17.0 & 16.3 & $\cdot$ & $\cdot$ \\
\hline Lechuga & 6.9 & 7.0 & 2.1 & 1.4 & + & - & $\therefore$ & + & - & $\cdot$ \\
\hline Papa & 3.0 & 2.4 & 2.8 & 4.6 & 1.2 & 2.3 & 3.2 & 5.4 & 1.4 & 1.2 \\
\hline Rábano & & - & 13.9 & $11.9^{\circ}$ & - & $\because$ & - & $\therefore$ & $\therefore$ & - \\
\hline Tomate verde & $\cdot$ & - & $\therefore$ & $\cdot$ & $\cdot$ & $\cdot$ & .6 & 1.5 & 7.6 & 6.1 \\
\hline Zanahoria & & - & 12.3 & 11.0 & 10.4 & 11.5 & 11.2 & 12.9 & 3.4 & 5.2 \\
\hline Alpiste & 8.4 & 6.8 & 6.0 & 5.4 & 3.3 & 2.7 & 7.5 & 5.8 & 4.1 & 2.6 \\
\hline Cebada forrajera & 1.8 & 7.1 & 1.4 & 2.5 & 2.3 & 6.6 & 2.3 & 1.1 & 1.7 & 2.2 \\
\hline Ebo veza & $\cdot$ & • & 14.6 & 11.8 & $\therefore$ & $\therefore$ & - & $\therefore$ & $\therefore$ & - \\
\hline \multirow[t]{3}{*}{ Maiz forrajero } & - & ? & 4.1 & 2.8 & 2.1 & 3.4 & 1.6 & 1.1 & 1.4 & .9 \\
\hline & \multicolumn{2}{|c|}{1977} & \multicolumn{2}{|c|}{1978} & \multicolumn{2}{|c|}{1979} & \multicolumn{2}{|c|}{1980} & \multicolumn{2}{|c|}{1981} \\
\hline & $1=$ & 2 & 1 & 2 & 1 & 2 & 1 & 2 & 1 & 2 \\
\hline Pastos & - & - & 1.4 & 2.0 & 1.7 & 1.3 & 2.3 & 1.9 & - & - \\
\hline Remolacha forrajera & $\cdot$ & $\cdot$ & 14.6 & 2.6 & $\cdot$ & $\cdot$ & $\cdot$ & $\cdot$ & 2.2 & 1 \\
\hline Sorgo forrajero & 1.5 & 2.7 & 1.6 & 1.9 & 1.2 & 1.4 & 1.5 & 1.5 & 1.8 & 1.4 \\
\hline Trigo forrajero & - & - & - & • & • & - & $\cdot$ & - & 3.7 & 3.2 \\
\hline Girasol & - & $\cdot$ & $\cdot$ & $\cdot$ & $\cdot$ & $\cdot$ & 1.5 & 2.9 & - & - \\
\hline Sorgo para escoba & 6.7 & 4.6 & 7.1 & 5.5 & 7.1 & 4.2 & 7.1 & 3.5 & 6.0 & 5.7 \\
\hline Mandarina & : & $\therefore$ & 14.0 . & 12.3 & 13.8 & 13.9 & 16.2 & 15.6 & 14.3 & 12.0 \\
\hline Naranja & 9.5 & 9.9 & 10.0 & 9.1 & 8.7 & 6.7. & 11,0 & 8.7 & 9.8 & 7.1 \\
\hline Toronja & 12.1 & 14.2 & 7.3 & 8.2 & 8.2 & 7.7 & 11.1 & 11.7 & 10.2 & 6.5 \\
\hline Aguacate & 6.2 & 8.6 & 6.1 & 5.2 & 5.8 & 5.7 & 8.8 & 8,0 & 12.0 & 9.5 \\
\hline C. de almendra & $\cdot$ & $\cdot$ & 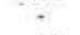 & $\cdot$ & $\cdot$ & $\cdot$ & $\cdot$ & $\cdot$ & 1.4 & 2.2 \\
\hline Chabacano & .3 & 1.2 & .5 & 1.1 & - & $\cdot$ & - & - & .4 & 1.5 \\
\hline Dátil & $\cdot$ & $\cdot$ & 4.1 & 11.6 & $\cdot$ & $\cdot$ & $\cdot$ & $\cdot$ & $\cdot$ & $\therefore$ \\
\hline Durazno & 1.2 & 7.1 & 2.3 & .7 & 1.5 & .4 & - & - & 1.6 & 1.2 \\
\hline Guayaba & .1 & 1.4 & $\cdot$ & $\cdot$ & 2.4 & 3.8 & $\cdot$ & * & 15.2 & 10.1 \\
\hline Higo & $\cdot$ & - & 1.1 & 1.1 & - & - & - & - & 1.1 & 1.1 \\
\hline Mango & - & $\cdot$ & $\therefore$ & $\cdot$ & $\therefore$ & $\therefore$ & $\cdot$ & $\cdot$ & 2.4 & 24 \\
\hline Manzana & .4 & .7 & 1.4 & 1.7 & 1.0 & 1.3 & - & $\cdot$ & 1.0 & 1.7 \\
\hline Membrillo & is & $\therefore$ & 1.9 & 1.7 & 13.8 & 13.9 & $\therefore$ & $\therefore$ & $\therefore$ & - \\
\hline Nuez de Castilla & 6.5 & 2.1 & 6.9 & 3.5 & $\cdot$ & $\cdot$ & 3.9 & 3.1 & 3.1 & 2.8 \\
\hline Papaya & $\cdot$ & $\therefore$ & 12.4 & 7.4 & $\therefore$ & $\therefore$ & $\therefore$ & $\therefore$ & 2.4 & 1.4 \\
\hline Pera & .8 & 7.2 & 5.2 & 1.5 & 3.9 & 3.5 & 4.0 & 3.5 & 3.5 & 1.7 \\
\hline Uva & - & - & - & • & 4.4 & 4 & - & - & 8.7 & 1.7 \\
\hline
\end{tabular}

1 - Superficie cosechada

2-Valor cosechado 
ANEXO III.6 Cocientes de localización por producto. Estado de Tamaulipas. 1977-1981.

\begin{tabular}{|c|c|c|c|c|c|c|c|c|c|c|}
\hline & \multicolumn{2}{|c|}{1977} & \multicolumn{2}{|c|}{1978} & \multicolumn{2}{|c|}{1979} & \multicolumn{2}{|c|}{1980} & \multicolumn{2}{|c|}{1981} \\
\hline & 1 & 2. & 1 & 2 & 1. & 2 & 1 & 2 & 1. & 2 \\
\hline Arroz palay & in & - & 2.6 & 4.9 & 3.4 & 7.2 & 2.4 & 3.0 & 2.5 & 2.5 \\
\hline Arvcjón & - & - & - & - & . & - & 2.4 & 3.0 & - & - \\
\hline Frijol & - & - & .5 & 1.1 & .5 & 1.3 & & - & - & . \\
\hline Maíz & 1.6 & 3.2 & 1.5 & 3.5 & 1.1 & 4.1 & 1.6 & 2.4 & - & - \\
\hline Maiz palomero & 2.9 & 2.3 & 2.9 & 5.3 & 3.3 & 6.9 & 2.4 & 3.0 & 2.5 & 2.3 \\
\hline Sorgo en grano & 2.2 & 3.3 & 2.4 & 4.2 & 2.9 & .0 & 2.1 & 2.6 & 2.1 & .1 \\
\hline Brócoli & 2.9 & 4.7 & 2.9 & 5.7 & 2.9 & 6.5 & 1.8 & 1.4 & & \\
\hline Calabacita tuerna & 1.2 & 9 & • & - & 1.0 & .6 & 1.3 & 1.4 & - & - \\
\hline Calabaza & - & & & - & - & - & 2.1 & .9 & - & - \\
\hline Cebolla & - & - & 1.0 & 1.3 & .8 & 1.8 & 1.0 & 1.1 & .7 & 1.5 \\
\hline Col de Bruselas & - & $=$ & 2.9 & 5.0 & $\therefore$ & & - & - & - & - \\
\hline Coliflor & 2.9 & 4.7 & 2.5 & 4.6 & .9 & 3,4 & 1.2 & .4 & - & - \\
\hline Col o repollo & 3.5 & 4.3 & 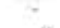 & & - & - & - & - & - & - \\
\hline Chile verde & $\because$ & - & .7 & 1.7 & . & - & - & - & - & - \\
\hline Ejote & 2.9 & 4.0 & 2.6 & 2.3 & 2.5 & 2.3 & 2.1 & 1.1 & 1.9 & .8 \\
\hline Elote & • & - & • & - & - & - & - & - & 1.8 & 1.9 \\
\hline Lechuga & 6.9 & 7.0 & - & - & $\cdots$ & & - & - & - & - \\
\hline Melón & - & - & .8 & 1.8 & .8 & 1.6 & .8 & 1.0 & - & - \\
\hline Nabo & 2.9 & 6 & 2.9 & 4.5 & & $=$ & 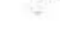 & - & - & - \\
\hline Nopalitos & - & - & - & - & 3.4 & 7.2 & - & - & - & - \\
\hline Ocra & 2.9 & 4.7 & 2.9 & 5.7 & 3.4 & 7.2 & 2.4 & 3.0 & 2.5 & 2.5 \\
\hline Papa & 3.0 & 2.4 & - & $\cdot$ & - & - & - & - & - & - \\
\hline \multirow[t]{3}{*}{ Pepino } & - & - & $\cdot$ & - & 1.0 & .1 & 2.4 & .3 & - & - \\
\hline & \multicolumn{2}{|c|}{1977} & \multicolumn{2}{|c|}{1978} & \multicolumn{2}{|c|}{1979} & \multicolumn{2}{|c|}{1980} & \multicolumn{2}{|c|}{1981} \\
\hline & 1 & 2 & 1 & 2 & 1 & 2 & 1 & 2 & 1 & 2 \\
\hline Sandia & * & - & 1.0 & 1.9 & 1.0 & 1.2 & - & - & - & * \\
\hline Tomate rojo & - & - & - & - & 1.6 & 1.7 & - & - & - & \\
\hline Tomate verde & - & - & 1.3 & 1.7 & 2.3 & 1.4 & 1.9 & 1.7 & - & - \\
\hline Pastos & - & - & 3 & 1.1 & .6 & 1.7 & .3 & 1.0 & 2.3 & 1.9 \\
\hline Sorgo forrajero & - & $\cdot$ & - & $\cdot$ & 5 & 1.6 & - & - & - & - \\
\hline Triticale forrajero & 1.5 & 2.7 & - & - & - & - & - & - & - & $=$ \\
\hline Cártamo & 1.4 & 6 & 1.6 & 12 & 1.2 & 1.1 & 1.2 & 8 & 1.3 & .8 \\
\hline Girasol & 2.4 & 1,8 & 1.9 & 1.5 & 2.6 & 3.3 & 2.6 & 3.7 & 2.9 & 4.0 \\
\hline Snya & - & - & - & $\cdot$ & 1.1 & 1.1 & 1.6 & 1.9 & 2.1 & 2.6 \\
\hline Hencquén & 2.9 & 4.3 & 2.9 & 5.4 & 3.4 & 7.0 & 2.4 & 2.7 & 2.5 & 2.4 \\
\hline Caña de azúcar & 2.4 & 2.4 & 2.4 & 3.0 & 3.4 & 7.1 & 2.9 & 5.6 & 2.9 & 4.7 \\
\hline Limón y lima & 2.6 & 4.0 & 2.6 & 3.7 & 2.8 & 5.4 & 2.0 & 1.4 & 2.2 & 1.8 \\
\hline Mandarina & 14.0 & 12.3 & • & - & 2.1 & 3.2 & • & - & - & - \\
\hline Naranja & 10.0 & 9.1 & .8 & 1.6 & .8 & 1.7 & 1.1 & 3.2 & .7 & 1.0 \\
\hline Toronja & 7.3 & 8.2 & 1.2 & 1.5 & - & - & 1.2 & 2.7 & - & - \\
\hline Aguacate & 1.3 & 1.9 & 1.6 & 3.3 & 1.9 & 4.2 & - & - & - & - \\
\hline C. de almendra & - & - & 1.1 & 1.1 & - & - & - & - & - & - \\
\hline Chabacano & .3 & 1.2 & - & - & - & - & - & - & - & - \\
\hline Durazno & 12 & 7.1 & - & - & - & - & - & - & - & - \\
\hline Guayaba & .1 & 1.4 & - & - & - & - & - & - & - & - \\
\hline Mango & 2.6 & 3.5 & 2.6 & 5.1 & 3.2 & 6.9 & - & 3.0 & 2 & 1.4 \\
\hline Piña & - & - & - & - & 3.4 & 7.2 & - & 3.0 & - & - \\
\hline Papayal & - & - & - & - & - & - & - & 2.3 & - & - \\
\hline Tamarindo & 2,9 & 4.7 & - & $\cdot$ & 3.4 & 7.1 & - & 3.0 & 2.5 & 2.2 \\
\hline
\end{tabular}


ANEXO IV 1a. Análisis de cambio participativo. Región fronteriza del norte de México. Superficie cosechada 1977-1981; exportación directa.

\begin{tabular}{|c|c|c|c|c|c|c|}
\hline \multirow[b]{2}{*}{ ESTADO } & \multicolumn{3}{|c|}{$1977-1978$} & \multicolumn{3}{|c|}{1978.1979} \\
\hline & Composición & Crecimiento & Cambio global & Composición & Crecimiento & Cambio global \\
\hline Baja California & -0.002530 & 0.078407 & 0.0758768 & -0.022839 & -0.090566 & -0.1134049 \\
\hline Sonora & 0.177396 & -0.135602 & 0.0417940 & 0.368918 & -0.171182 & 0.1977368 \\
\hline Chihuahua & 0.003130 & 0.016232 & 0.0193617 & 0.002136 & -0.107744 & -0.1056078 \\
\hline Coahuila & -0.017760 & -0.026466 & -0.0442257 & -0.235683 & 0.485263 & 0.2495805 \\
\hline Nuevo León & 2.313522 & -2.215349 & 0.0981734 & -0.311929 & -0.098743 & -0.4106722 \\
\hline \multirow[t]{2}{*}{ Tamaulipas } & 0.230838 & -0.372805 & -0.1419675 & -0.152016 & -0.111686 & -0.2637017 \\
\hline & \multicolumn{3}{|c|}{1979.1980} & \multicolumn{3}{|c|}{$1980-1981$} \\
\hline ESTADO & Composición & Crẹcimiento & Cambio global & Composición & Crecimiento & Cambio global \\
\hline Baja California & 0.081925 & 0.020659 & 0.1025847 & 0.162271 & -0.010712 & 0.1515585 \\
\hline Sonora & 0.029320 & -0.316377 & -0.2870577 & 0.146235 & -0.061086 & 0.0851493 \\
\hline Chihuahua & 0.093473 & -0.038851 & 0.0546223 & 0.072548 & -0.084635 & -0.0120868 \\
\hline Coahuila & -0.117160 & -0.080879 & -0.1980386 & $0.155 ̧ 609$ & -0.110152 & 0.0454564 \\
\hline Nuevo León & 0.088908 & 0.172497 & 0.2614044 & 0.033357 & -0.016692 & 0.0166646 \\
\hline Tamaulipas & 120.275200 & -117.653500 & 2.6217500 & 0.174789 & -0.733481 & -0.5586915 \\
\hline
\end{tabular}


ANEXO IV 1b. Análisis de cambio participativo. Región fronteriza del norte de México. Valor cosechado 1977-1981; exportación directa.

\begin{tabular}{|c|c|c|c|c|c|c|}
\hline \multirow[b]{2}{*}{ ESTADO } & \multicolumn{3}{|c|}{$1977-1978$} & \multicolumn{3}{|c|}{$1978 \cdot 1979$} \\
\hline & Composición & Crecimiento & Cambio global & Composición & Crecimiento & Cambio global \\
\hline Baja California & 0.077966 & 0.172240 & 0.2502062 & 2.972827 & -3.021798 & -0.0489707 \\
\hline Sonora & -0.075960 & -0.222774 & -0.1468138 & 0.313012 & -0.175970 & -0.1370427 \\
\hline Chihuahua & $-0.011132^{\circ}$ & 0.057176 & 0.0460440 & -0.020682 & -0.174831 & -0.1955123 \\
\hline Coahuila & 0.016660 & -0.092443 & -0.0757821 & -0.033118 & 0.159174 & 0.1260560 \\
\hline Nuevo León & 1.452697 & -0.771241 & 0.6814556 & 0.184557 & -0.505967 & -0.3214103 \\
\hline \multirow[t]{2}{*}{ Tamaulipas } & 0.275871 & -0.216991 & 0.0588803 & 0.586840 & -0.369343 & 0.2174975 \\
\hline & \multicolumn{3}{|c|}{$1979-1980$} & \multicolumn{3}{|c|}{$1980-1981$} \\
\hline ESTADO & Composicion & Crecimiento & Cambio global & Composicion & Crecimiento & Cambio global \\
\hline Baja California & 0.201256 & 0.1955001 & 0.3962565 & -0.069643 & -0.419485 & 0.4891280 \\
\hline Sonora & 0.091964 & -0.239048 & -0.1470845 & 0.201832 & -0.097258 & 0.1045740 \\
\hline Chihuahua & 0.116728 & 0.045037 & 0.1617650 & 0.142127 & -0.102465 & 0.0396615 \\
\hline Coahuila & 0.033425 & -0.330984 & -0.2975597 & 0.411229 & -0.238212 & 0.1730173 \\
\hline Nuevo León & 0.029436 & 0.178185 & 0.2076215 & 0.090074 & 0.062084 & 0.1521580 \\
\hline Tamaulipas & 0.062520 & -0.295117 & -0.2325974 & 0.739059 & -0.252278 & 0.4867816 \\
\hline
\end{tabular}


ANEXO IV 2a. Análisis de cambio participativo. Región fronteriza del norte de México. Superficie cosechada. 1977-1981; exportación indirecta. (Forrajes).

\begin{tabular}{|c|c|c|c|c|c|c|}
\hline \multirow[b]{2}{*}{ ESTADO } & \multicolumn{3}{|c|}{$1977 \cdot 1978$} & \multicolumn{3}{|c|}{$1978-1979$} \\
\hline & Composición & Crecimiento & Cambio global & Composicion & Crecimiento & Cambio global \\
\hline Baja California & 0.122050 & 0.064204 & 0.1862540 & 0.211296 & $-0,320401$ & -0.10910 .53 \\
\hline Sonora & -0.103363 & 0.002575 & -0.1007877 & 0.261777 & -0.283675 & -0.0218978 \\
\hline Chihuahua & 0.156991 & -0.508329 & -0.3113380 & 0.275494 & -0.526614 & -0.2508197 \\
\hline Coahuila & 0.178198 & -0.003639 & 0.1745584 & 0.133054 & -0.005564 & 0.1274907 \\
\hline Nuevo León & 0.464359 & 0.265312 & 0.7296706 & 0.005418 & -0.141884 & -0.1364656 \\
\hline Tamaulipas & -0.253037 & 0.020066 & -0.2329708 & 0.137583 & 0.424066 & 0.2864832 \\
\hline \multirow[b]{2}{*}{ ESTADO } & \multicolumn{3}{|c|}{$1979-1980$} & \multicolumn{3}{|c|}{$1980 \cdot 1981$} \\
\hline & Composición & Crecimiento & Cambio global & Composición & Crecimiento & Cambio global \\
\hline Baja California & -0.001974 & -0.201806 & -0.2037796 & 4.782989 & -6.810290 & -2.0273010 \\
\hline Sonora & 0.019696 & 0.026336 & 0.0459412 & 2.272986 & -3.662357 & -1.3893720 \\
\hline Chihuahua & 0.068552 & $-0.0810 \dot{4} 8$ & -0.0124959 & -0.108197 & -1.556149 & -1.6643460 \\
\hline Coahuila & 0.024559 & 0.024126 & 0.0486855 & -1.143856 & -0.912283 & -2.0561390 \\
\hline Nuevo León & 0.040186 & -0.039492 & 0.0006939 & 1.844085 & -3.675737 & -1.8316520 \\
\hline Tamaulipas & 0.115925 & -0.076290 & 0.0396342 & 16.243490 & 42.801550 & 59.0450400 \\
\hline
\end{tabular}


ANEXO IV 2b. Análisis de cambio participativo. Región fronteriza del norte de México. Valor cosechado 1977-1981; exportación indirecta. (Forrajes).

\begin{tabular}{|c|c|c|c|c|c|c|}
\hline \multirow[b]{2}{*}{ ESTADO } & \multicolumn{3}{|c|}{$1977-1978$} & \multicolumn{3}{|c|}{$1978 \cdot 1979$} \\
\hline & Composición & Crecimiento & Cambio global & Composición & Crecimiento & Cambio global \\
\hline Baja California & 0.005935 & -0.050886 & -0.0449503 & 0.509482 & -0.349720 & 0.1597621 \\
\hline Sonora & 0.396036 & -0.456720 & -0.8527554 & 0.297222 & 0.170982 & 0.4682041 \\
\hline Chihuahua & 0,076322 & -0.339156 & -0.2628347 & 0,231324 & 0.026941 & 0.2582652 \\
\hline Coahuila & 2.338968 & -1.146890 & 1.1920780 & 0.066212 & -0.437019 & 0.3708072 \\
\hline Nueva Lebn & 0.113579 & -0.130335 & -0.0167555 & 0.588810 & -0.205773 & 0.3030370 \\
\hline \multirow[t]{2}{*}{ Tamaulipas } & -0.304021 & 0.199386 & -0.1046357 & 0.950817 & 0.635781 & 1.5865990 \\
\hline & \multicolumn{3}{|c|}{$1979-1980$} & \multicolumn{3}{|c|}{$1980-1981$} \\
\hline ESTADO & Composición & Crecimiento & Cambio global & Composición & Crecimiento & Cambio global \\
\hline Baja California & 0.109505 & -0.505900 & -0.3963955 & 2.703220 & -3.122185 & -0.4189651 \\
\hline Sonora & 0.049834 & 0,261584 & 0.3114181 & 0.678293 & -1.423727 & -0.7454338 \\
\hline Chihuahua & 0.005008 & 0.097367 & 0.1023757 & 0.252043 & -1.337409 & -1.0853660 \\
\hline Coahuila & 0.040975 & -1.211233 & 0.0862607 & 0.167113 & -1.211233 & -1.0441200 \\
\hline Nuevo León & 0.003754 & -0.196146 & -0.1923916 & 1.648369 & -2.928606 & 1.2802370 \\
\hline Tamaulipas & -0.050348 & 0.331594 & 0.2785466 & 9.517494 & 2.649798 & 12.1672900 \\
\hline
\end{tabular}


ANEXO IV 3a. Análisis de cambio participativo. Región fronteriza del norte de México. Superficie cosechada. 1977-1981; mercado interno. (Dieta básica).

\begin{tabular}{|c|c|c|c|c|c|c|}
\hline \multirow[b]{2}{*}{ ESTADO } & \multicolumn{3}{|c|}{$1977-1978$} & \multicolumn{3}{|c|}{$1978-1979$} \\
\hline & Composicibn & Crecimiento & Cambio global & Composición & Crecimiento & Cambio global \\
\hline Baja California & -0.024587 & 0.192445 & 0.1678580 & 0.137958 & -0.137722 & 0.0002362 \\
\hline Sonora & 0.189571 & 0.213913 & 0.4034836 & -0.121413 & -0.050313 & -0.171 .7261 \\
\hline Chihuahua & 0.168056 & -0.016822 & 0.1512346 & 0.183649 & 0.016395 & -0.1672537 \\
\hline Coahuila & -0.168137 & -0.035074 & -0.2032114 & 0.539724 & 0.114234 & 0.1443596 \\
\hline Nuevo León & -0.018249 & -0.094135 & -0.1123842 & 0,134434 & 0.009925 & 0.1443596 \\
\hline \multirow[t]{2}{*}{ Tamaulipas } & -0.107699 & -0.080862 & -0.1885607 & -0.384943 & 0.161244 & -0.2236988 \\
\hline & \multicolumn{3}{|c|}{1979.1980} & \multicolumn{3}{|c|}{$1980-1981$} \\
\hline ESTADO & Composición & Crecimiento & Cambio global & Composicibn & Crecimiento & Cambio global \\
\hline Baja California & -0.247310 & 0.138597 & -0.1087129 & -0.345682 & -0.002484 & -0.3481651 \\
\hline Sunora & -0.246387 & 0.059953 & -0.1864347 & 0.013415 & 0.123834 & 0.1372488 \\
\hline Chihuahua & -0.410962 & 0.095269 & -0.3156927 & 0.481427 & 0.038436 & 0.5198633 \\
\hline Coahuila & -0.846533 & 0.587122 & -0.2594111 & 0.519477 & 0.021138 & 0.5406150 \\
\hline Nuevo León & -0.289506 & 0.037478 & 0.2520283 & 0.364027 & -0.025736 & 0.3382909 \\
\hline Tamaulipas & 0.596493 & 0.047412 & 0.6439048 & -0.512127 & 0.039478 & -0.4726489 \\
\hline
\end{tabular}


ANEXO IV 3b. Análisis de cambio participativo. Región fronteriza del norte de México. Valor cosechado. 1977-1981; mercado interno. (Dieta básica).

\begin{tabular}{|c|c|c|c|c|c|c|}
\hline \multirow[b]{2}{*}{ ESTADO } & \multicolumn{3}{|c|}{$1977 \cdot 1978$} & \multicolumn{3}{|c|}{$1978 \cdot 1979$} \\
\hline & Composicion & Crecimiento & Cambio global & Composición & Crecimiento & Cambio global \\
\hline Baja California & -0.327355 & 0.245031 & -0.0823242 & 0.220097 & 0.096343 & 0.3164400 \\
\hline Sonora & 0.218485 & 0.117436 & 0.3359208 & -0.174505 & 0.072261 & -0.1022432 \\
\hline Chihuahua & 0.168087 & 0.307246 & 0.4753329 & -0.054085 & -0.018895 & -0.0729798 \\
\hline Coahuila & -0.601681 & 0.423709 & -0.1779715 & 0.222801 & 0.063598 & 0.2863990 \\
\hline Nuevo Lebn & 0.160848 & 0.160848 & 0.4716752 & -0.323506 & 0.017172 & -0.3063339 \\
\hline \multirow[t]{2}{*}{ Tamaulipas } & -0.174013 & -0.067076 & -0.2410883 & -0.065491 & 0.186710 & 0.1212192 \\
\hline & \multicolumn{3}{|c|}{1979.1980} & \multicolumn{3}{|c|}{$1980-1981$} \\
\hline ESTADO & Composición & Crecimiento & Cambio global & Composicion & Crecimiento & Cambio global \\
\hline Baja California & -0.156789 & -0.003526 & -0.1603157 & -0.621446 & 0.062764 & -0.5586822 \\
\hline Sonora & -0.210380 & 0.132452 & -0.0779277 & 0.122192 & 0.102192 & 0.1113986 \\
\hline Chihuahua & -0.622911 & 0.069605 & -0.5533052 & 0.874535 & 0.301639 & 1.1761740 \\
\hline Coahuila & -0.442152 & 0.292539 & -0.1496127 & 0.406807 & 0.161883 & 0.5686893 \\
\hline Nuevo León & -0.157599 & -0.157599 & -0.2101134 & 0.133886 & 0.017508 & 0.1513933 \\
\hline Tamaulipas & 0.071231 & 0.351833 & 0.4230639 & -0.657945 & 0.213769 & -0.4441756 \\
\hline
\end{tabular}

